\title{
PREDICTING THE SCHEDULE AND COST PERFORMANCE IN PUBLIC SCHOOL BUILDING PROJECTS IN TAIWAN
}

\author{
Yi-Kai JUAN (1) ${ }^{*}$, Ling-Er LIOU ${ }^{1,2}$ \\ ${ }^{1}$ Department of Architecture, National Taiwan University of Science and Technology, Taipei, Taiwan \\ ${ }^{2}$ Department of Secretarial Affairs, Ministry of Education, Taipei, Taiwan
}

Received 11 December 2020; accepted 5 October 2021; first published online 20 December 2021

\begin{abstract}
The Ministry of Education (MOE) of Taiwan invests about NTD 30 billion a year in Public School Building Projects (PSBPs). However, 95\% of the PSBPs have been extended and have incurred increased costs. A PSBP performance evaluation and prediction system was established by using the Fuzzy Delphi Method (FDM), association rules and an Artificial Neural Network (ANN). Sixty-two Taiwanese PSBPs were used as the samples, while eleven high correlation factors that influence the project performance of PSBPs were defined, and the reasons leading to the poor project performance were discussed in this study. Moreover, the results of the test cases operated by ANN showed that the accuracy rate for schedule and cost variability predictions can reach $84 \%$. The high accuracy rate indicated the reliability of priority control for high-risk projects in the future. The proposed approach can be provided to clients, design and construction firms, and project managers to understand the project performance in real time and to establish a dynamic tracking review and response measures for improving the overall project satisfaction.
\end{abstract}

Keywords: public school building projects (PSBPs), project performance, Fuzzy Delphi Method (FDM), association rules, Artificial Neural Network (ANN).

\section{Introduction}

According to statistics provided by the Ministry of Education (MOE) of Taiwan in 2020, it is involved in more than 900 public school projects, with a total budget of up to NTD 30 billion (about USD 1 billion) (Public Construction Commission, 2020). The initial planning and design period for a Public School Building Project (PSBP) in Taiwan will increase six months to one year on average compared with the original schedule, and the construction time will also increase by one to two years (Public Construction Commission, 2020). In executing the existing PSBPs, poor budget execution efficiency, the prolonged duration of projects, poor work quality, performance disputes, and other situations have often led to poor overall performance (Bagaya \& Song, 2016).

Most of the early studies on project performance evaluation have focused on establishing indicators and frameworks to measure the performance of a project (Bassioni et al., 2004; Bryde \& Wright, 2007; Lin et al., 2011), and various multi-criteria quantitative evaluation methods have been developed for an indicator weight analysis (Rozenes et al., 2004; Zavadskas et al., 2014). With the development of information technology, various artificial intelligence methods have been applied to the prediction of project performance in different fields of Architecture, Engineering, and Construction (AEC) industries, such as cost and schedule success of building projects in the early planning stage (Wang et al., 2012), cost estimation of construction projects in the biding stage (Aretoulis et al., 2006), productivity prediction of machines on construction sites (Hola \& Schabowicz, 2010; Armaghani et al., 2017), cost estimation of bridge superstructures (Fragkakis et al., 2010), cost prediction of public highway projects (Aretoulis, 2019), cost estimation of road tunnel construction (Petroutsatou et al., 2011), and impact assessment of geotechnical construction and blasting operation (Huang et al., 2020; Li et al., 2021; Mohamad et al., 2014).

A review of the existing literature indicates that there are still some limitations in the current project performance prediction. Due to the increasingly complex projects and the long duration of projects, the accuracy of performance prediction is easily influenced by various internal and external factors in the project execution pro-

${ }^{*}$ Corresponding author. E-mail: rik@mail.ntust.edu.tw 
cess. In other words, the performance prediction must be dynamic. In addition, from the perspective of risk management, it is important to understand the factors that influence project performance by using systematical methods, as well as controlling and managing them to achieve early warnings, in project management.

The main purpose of this study is to establish a PSBP performance evaluation and prediction system that can be applied at the beginning of a project. Only PSBPs for public (national) universities were selected as samples because they are administrated and financially supported by the MOE of the Taiwan General government, which has established a sound database for project management. In other words, the PSBPs for K-12 (kindergarten through to Twelfth Grade) were excluded from this study. The study was conducted in three phases: firstly, by referring to the literature and interviews with experts, a questionnaire on the factors influencing the performance of PSBPs was prepared, and the critical influential factors were selected by the Fuzzy Delphi Method (FDM). Secondly, based on 62 PSBPs in Taiwan, the data of corresponding critical factors and performance were collected, and the association rules of data mining were used to mine the relationship between the performance and critical factors. Finally, the performance predictions of planning and design, bidinviting, and construction phase were established by the ANN. This prediction model can be imported in various phases of a project's lifecycle to achieve dynamic continuous monitoring. The limitations, application opportunities, and response measures of the prediction model, as well as the suggestions for future studies, are explained later in this study.

\section{Problem statement}

There are three common reasons causing poor PSBP performance in Taiwan (National Development Council [NDC], 2020; Public Construction Commission, 2020). Firstly, the projects are highly complex and require numerous interfaces to be integrated, but government sectors cannot effectively control the performance of every project due to a lack of manpower and capacity. Secondly, it is difficult to fully consider the risks in different phrases of a project's life cycle due to the large amount of money involved and the large number of projects in progress. Finally, because the representatives of the general affairs in schools lack professional knowledge and experience in project procurement, or because they are unfamiliar with bid-inviting and awarding methods, there are many disputes over contractor selection and the execution of contract management. In the face of the above-mentioned problems, the MOE is under great pressure and a heavy workload, and therefore hopes to develop a performance prediction model to provide early warnings and monitoring of high-risk PSBPs.

Many studies have explored the performance prediction of building projects based on statistical regression and artificial intelligence techniques (Alaloul et al., 2018;
Barraaza et al., 2000; Ling \& Liu, 2004; Wang et al., 2012). For instance, Ling and Liu (2004) predicted project performance with the Artificial Neural Network (ANN), based on the data of 33 turn-key projects in Singapore. Doloi et al. (2012) defined the critical factors influencing project performance by factor analysis and regression modeling, for the common problem of building project delays in India. Wang et al. (2012) predicted the costs and duration of projects with the ANN and support vector machine classification models, and pointed out that if prediction mechanisms are imported in the initial planning phase of the projects, they will have a significant impact on the success of the projects in the future. Alaloul et al. (2018) established building project performance prediction by using the ANN to define 16 critical factors, which verified the accuracy of its predictions.

However, only a few have focused on school building projects. Chen and Huang (2006) adopted the regression and neural network models to predict the cost and duration of projects for the reconstruction of schools in quakedamaged areas in Taiwan. They used the "floor area" as the independent variable for cost prediction, and "floor area" and "cost" as the independent variables for the prediction of the duration. Although the study revealed the potential of applying ANN techniques for yielding better prediction results, only one or two independent variables were selected for the prediction model, which may decrease the applicability and reliability of the performance prediction of school building projects. Al-Momani (1996) also applied multiple linear regression to predict the construction costs of public school buildings. However, their study was limited to an examination of the construction costs of school buildings, due to the wide variety of construction projects, which led to difficulties in data collection, and only eight variables were employed in the analysis of the construction costs. Shrestha and Zeleke (2018) explored the effect of change order on cost and schedule overruns of school building renovation projects, and the result revealed that the change orders increased the project cost by $3.56 \%$ and about $40 \%$ of these projects faced schedule overruns due to change orders.

In terms of project management, the previous studies have a number of limitations. Firstly, there is little research on the project performance evaluation and management of school buildings. Secondly, more factors that might influence the project performance should be taken into account. Finally, performance prediction and evaluation should cover different stages of the building life cycle more broadly, not just in the initial planning or construction stage.

\section{Establishment of factors influencing project performance}

Different perspectives (or stakeholders) offer different interpretations of the studies on project performance. For construction companies, there used to be many techniques and tools to measure project performance (Nas- 
sar \& AbouRizk, 2014); for instance, the S-curve method (Cristóbal, 2017), the Program Evaluation and Review Technique (PERT) (Hajdu \& Bokor, 2016), the EarnedValue Management System (EVMS) (Fleming \& Koppelman, 2010), and the Stochastic S-curves (SS) (Barraaza et al., 2000). From the perspective of organizational operation methods, the Balanced Scorecard (BSc) and Excellence Foundation Quality Model (EFQM) can be used to measure project performance (Haponava \& Al-jibouri, 2012). However, the existing performance evaluation indicators are widely questioned because they focus on the measurements after the completion of a project. Haponava and $\mathrm{Al}$-jibouri (2012) proposed that to achieve effective performance control, the concept of performance evaluation should be imported in the different phases of a project's lifecycle.

Many studies have explored the establishment of a comprehensive performance measurement structure and model, which consider not only the traditional dimensions, such as the cost, schedule, and quality, but also the dimensions of people and the environment. For instance, Baccarini (1999) defined a successful project as one that meets four indicators, namely, the schedule, cost, quality and owner satisfaction. Ling and Liu (2004) established performance evaluation factors for 11 turn-key projects, according to the four indicators. Bryde and Wright (2007) proposed a five-factor model, including cost, schedule, quality, customers, and project team dimensions, to measure successful projects. Ahadzie et al. (2008) established the critical success criteria for the building projects of developing countries, including their environmental impact, customer satisfaction, as well as the quality, cost, and time. The focus and trend of project performance evaluation includes the following two points: 1) the different phases of a lifecycle shall be considered in project performance measurement; the indicators are mostly used for review purposes after a project is completed, and they do not offer the opportunity for control during the project development and execution; 2) for measurement indicators, in addition to the traditional cost, project duration, and quality, the measurement scope should be extended to the external environment, or human factors, of the project.

If the four-indicator framework, established by Baccarini (1999) and Ling and Liu (2004), is taken as the basis, then the sound project performance management indicators will include the project schedule, the cost, the quality, and owner satisfaction. For the Taiwanese PSBPs, the competent authority is the MOE. In the project management evaluation of this MOE, quality and owner satisfaction are actually incorporated into the cost and schedule variability. In other words, the authorities have been able to effectively understand the project quality and satisfaction by controlling the cost and the schedule. In addition, all PSBPs are awarded according to the Government Procurement Act, and a project's lifecycle includes the following phases: planning and design, bid-inviting, construction, and operation and maintenance management. In this study, in order to establish an effectively-phased early warning mechanism, the project scope is set as performance evaluation in the planning and design, bid-inviting, and construction phases, which is in line with the proposal of Haponava and Al-jibouri (2012) that the concept of performance evaluation should be imported into the project's lifecycle.

This study examines some of the literature that has identified the factors influencing project performance. Enshassi et al. (2008) proposed 61 factors that influence project performance, with the main factors being delays because of material shortages, the unavailability of resources, the low level of project leadership skills, the escalation of material prices, the unavailability of highlyexperienced and qualified personnel, and the poor quality of the available equipment and raw materials. Santoso and Gallage (2019) proposed that 11 dimensions and 66 factors influence a project's performance, and pointed out that the 10 critical factors that have been identified by clients and contractors are as follows: the scale and scope of the project, if it is large; site management and supervision by the contractor; the high complexity of the project; the inadequate planning and scheduling of activities by the contractor; the lack of experience; schedule delays; changes in government policies regarding the project; inaccurate cost estimates; construction errors and quality issues in the completed work; and inaccurate time estimates. Gunduz and Yahya (2018) reviewed a large number of studies on the factors influencing project performance, and they proposed 25 factors, including the company's financial strength, the scope and work definition, the completion of the design at start of the construction, political conflicts and corruption, unforeseen conditions, etc.

According to the literature, it is evident that the factors influencing project performance are classified differently by different researchers, but the basic structure can still be attributed to the problems caused by people (firms and owners), the projects, the operating procedures, the management methods, and the internal and external environment. They are also very similar to the five critical factors (Human-related Factors (HF), Project-related Factors (PF), Project Procedures (PP), Project Management actions (PM) and External Environment (EF)), as proposed by Sanvido et al. (1992), which influence the success of a project.

Based on the five major types of Sanvido et al. (1992), a total of 36 negative factors influencing the project performance of school buildings were preliminarily collected. As shown in Table 1, these factors were divided into two phases: 1) planning and design, together with bid-inviting; and 2) construction. There are two reasons of combining the planning and design with the bid-inviting phase in the following analysis. Firstly, the preparation of bid-inviting in Taiwan, including the provision of tender documentation and drawings, as well as the suggestions for the selection of contractors (e.g. the procurement and bid-inviting methods, the qualifications of the contractors, and the bidawarding methods), is usually conducted by planning and design firms. In other words, the two phases (planning 
and design, together with bid-inviting) are highly relevant in project lifecycle management. Secondly, according to the current regulations related to construction quality assurance, as proposed by the Public Construction Commission in Taiwan, the competent authority (the MOE) needs to inspect the project twice, in order to examine the performance of the project: the project progress must reach $30 \%$ of the planning and design phase (the first inspection), and $30 \%$ of the construction phase (the second inspection). In accordance with the current industry situation and the regulations, dividing the lifecycle of the project into the planning and design phase (which includes bid-inviting) and the construction phase is well-reasoned.

The factors shown in Table 1 may differ for public and private sector projects. For public building projects, they are generally regulated by the Government Procurement Act, especially for the processes of budget preparation and architect/contractor selection. In contrast, there are no such restrictions on private sectors projects. Therefore, factors such as procurement and bid-inviting methods, bid-awarding methods, the unit price of work items, budgeting, and firm performance could have significant impacts on projects in the public sector. In addition, the factors in Table 1 are also slightly different for public school

Table 1. Negative factors influencing the project performance of school buildings

\begin{tabular}{|c|c|c|}
\hline Phase & Factors & References \\
\hline \multirow{16}{*}{ 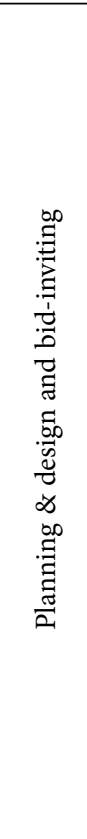 } & 1. Change of owner's demands (HF_1) & Doloi et al. (2012); Enshassi et al. (2008); Yang et al. (2010) \\
\hline & 2. Failure to complete pre-work (PM_1) & Jha and Iyer (2007); Leung et al. (2004) \\
\hline & 3. Long construction license examination procedures (PM_2) & NDC (2020) \\
\hline & 4. Failure of environmental impact evaluation (PF_1) & Chan et al. (2004); Tabish and Jha (2012); NDC (2020) \\
\hline & 5. Planning and design unit lacking ability and experience (HF_2) & $\begin{array}{l}\text { Jha and Iyer (2007); Sambasivan and Soon (2007); } \\
\text { Santoso and Gallage (2019) }\end{array}$ \\
\hline & 6. Plan complexity (PF_2) & $\begin{array}{l}\text { Gudiene et al. (2014); Patanakul et al. (2016); Santoso and } \\
\text { Gallage (2019) }\end{array}$ \\
\hline & 7. Large building scale (PF_3) & Patanakul et al. (2016); Santoso and Gallage (2019) \\
\hline & 8. Frequent planning design changes (PP_1) & Santoso and Gallage (2019) \\
\hline & 9. Ambiguous design drawing explanations (PP_2) & Santoso and Gallage (2019) \\
\hline & 10. Procurement and bid-inviting methods (PM_3) & $\begin{array}{l}\text { Chan et al. (2004); Mitkus and Trinkūnienè (2008); Santoso } \\
\text { and Gallage (2019) }\end{array}$ \\
\hline & 11. Bid-awarding methods (PM_4) & $\begin{array}{l}\text { Chan et al. (2004); Mitkus and Trinkūnienè (2008); Santoso } \\
\text { and Gallage (2019) }\end{array}$ \\
\hline & 12. Low unit price of work items (PP_3) & Enshassi et al. (2008); Santoso and Gallage (2019) \\
\hline & 13. Failure to set reasonable project duration (PP_4) & Santoso and Gallage (2019) \\
\hline & 14. Unreasonable budgeting (PP_5) & Enshassi et al. (2008); Santoso and Gallage (2019) \\
\hline & 15. Long accounting and capital auditing time (PM_5) & NDC (2020) \\
\hline & 16. Political factors (EE_1) & Chan et al. (2004); Tabish and Jha (2012) \\
\hline \multirow{20}{*}{ 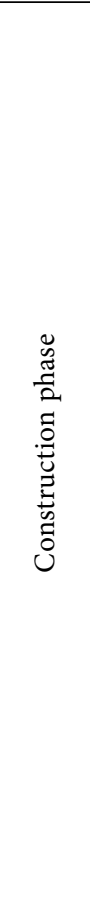 } & 17. Construction unit's poor performance in the past (HF_3) & Santoso and Gallage (2019) \\
\hline & 18. Firm's poor ability to fulfill contracts (HF_4) & Alzahrani and Emsley (2013); Santoso and Gallage (2019) \\
\hline & 19. Firm's poor financial condition (HF_5) & Alzahrani and Emsley (2013); Santoso and Gallage (2019) \\
\hline & 20. Complex project interfaces (PF_4) & Enshassi et al. (2008) \\
\hline & 21. Lack of construction materials (PP_6) & Enshassi et al. (2008); Kog and Loh (2012) \\
\hline & 22. Frequent construction design changes (PP_7) & Santoso and Gallage (2019) \\
\hline & 23. Poor construction and quality plans (PP_8) & Enshassi et al. (2008) \\
\hline & 24. Shutdown and termination (PP_9) & NDC (2020) \\
\hline & 25. Poor geological conditions (PF_5) & Faridi and El-Sayegh (2006) \\
\hline & 26. Poor acceptance of work (PM_6) & Faridi and El-Sayegh (2006) \\
\hline & 27. Failure to apply for fire control, water and electricity (PM_7) & NDC (2020) \\
\hline & 28. Construction influenced by extreme climate (EE_2) & Enshassi et al. (2008); Chan et al. (2004); Tabish and Jha (2012 \\
\hline & 29. Work safety problems (PF_6) & Enshassi et al. (2008) \\
\hline & 30. People's strikes or project disputes (EE_3) & Enshassi et al. (2008) \\
\hline & 31. Incomplete traffic maintenance plans (PP_10) & NDC (2020) \\
\hline & 32. Poor disposal plans for the remaining earthworks (PP_11) & NDC (2020) \\
\hline & 33. Labor shortage in the market (manpower shortage) (EE_4) & Enshassi et al. (2008); Faridi and El-Sayegh (2006) \\
\hline & 34. Special materials or construction methods (PM_8) & Enshassi et al. (2008); Faridi and El-Sayegh (2006) \\
\hline & 35. Evaluation and pricing methods (PP_12) & Santoso and Gallage (2019) \\
\hline & $\begin{array}{l}\text { 36. Other factors (such as excavation at historic sites, tree } \\
\text { transplantation) (EE_5) }\end{array}$ & Chan et al. (2004); Tabish and Jha (2012) \\
\hline
\end{tabular}


building and non-school building projects. For example, compared with other public building projects, school buildings are generally less complex and have fewer problems caused by special materials and construction methods, and because most of the buildings are on campus, they face fewer public strikes or fire control, water, and electricity application disputes.

\section{Research method and model construction}

\subsection{Research process}

The performance evaluation and prediction system proposed in this study can be roughly divided into three major aspects, namely, the people, the method, and the output, as shown in Figure 1. Firstly, when collaborating with the competent authority, namely the MOE, the study team defined the preliminary performance-influencing factors by referring to the literature on the performance of existing projects, and the database of Taiwan's Public Construction Commission (2020). Secondly, experts were invited for the FDM operation to select and confirm the factors. Next, the project database of the competent authority (the MOE) was obtained, and the sample selection and data collation of the association rules and ANN were confirmed, respectively. Finally, experts were invited again to discuss the obtained data mining results, and the response measures and strategies for future project management were summarized by in-depth qualitative interviews, in order to provide specific feedback to the competent authority.

\subsection{Model construction}

\subsubsection{Fuzzy Delphi Method (FDM)}

The traditional Delphi technique is prone to inconsistency and a convergence of expert opinions, which results in inefficiency (Kuo \& Chen, 2008). Murray et al. (1985) developed the FDM that combined the traditional Delphi method and the fuzzy theory to improve the vagueness and ambiguity of the Delphi method. Kaufmann and Gupta (1988) proposed another procedure of FDM, by using the fuzzy set theory to ask the respondents to give a three-point estimate (i.e. the conservative (C), moderate $(\mathrm{M})$, and optimistic $(\mathrm{O})$ values). The triangular fuzzy numbers (TFNs) were therefore formed to locate the three points of the extent of importance (i.e. the minimum (L), medium (M), and maximum (U) values), with a scale of $0-10$ points. These average values of experts were then calculated and depicted as two TFNs: one was the conservative TFN (CL, CM, CU), representing the minimum (L), medium $(\mathrm{M})$, and maximum $(\mathrm{U})$ values under conservative conditions, and the other is the optimistic TFN (OL, $\mathrm{OM}, \mathrm{OU})$, representing the minimum (L), medium (M), and maximum $(\mathrm{U})$ values under the optimistic conditions, as shown in Figure 2. The intersection of the experts' fuzzy opinions (area of grey triangle in Figure 2) indicated the



Figure 1. Research process diagram

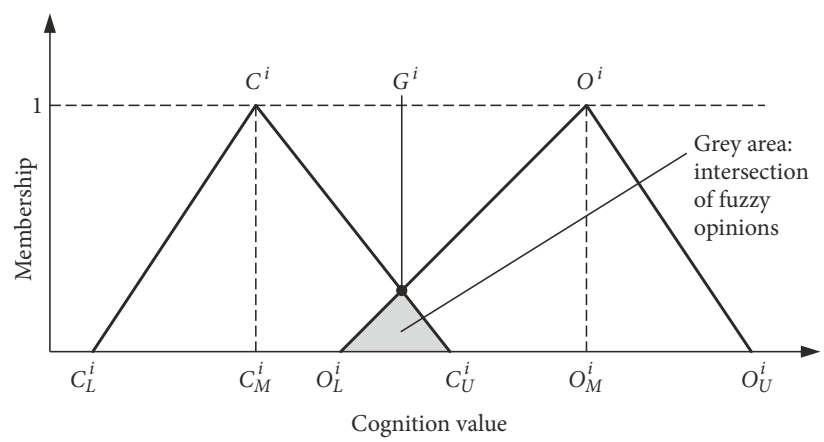

Figure 2. Triangular fuzzy numbers (TFNs) of FDM

consistency, or convergence, of the consensus. Finally, the consensus values $\left(G^{i}\right)$ of the survey items or questions can be obtained by calculating the geometric means of the conservative, moderate, and optimistic values (Wei \& Chang, 2008).

This study collected the opinions of experts from a questionnaire and also created the TFN as follows:

$$
\begin{aligned}
& \text { TFN }=\left(C^{i}, G^{i}, O^{i}\right) ; \\
& C^{i}=\min \left(X_{i j}\right) ; \\
& G^{i}=\sqrt[n]{\prod_{j=1}^{n} X_{i j} ;} \\
& O^{i}=\max \left(X_{i j}\right)
\end{aligned}
$$

where: $i$ is the number of indicators; $j$ is the number of experts; $C^{i}$ is the bottom of all the experts' evaluation value for indicator $i ; O^{i}$ is the ceiling of all the experts' evaluation value for indicator $i$; $G^{i}$ is the geometric mean of all the experts' evaluation values for indicator $i$; $X_{i j}$ is the evaluation value of the $j$ th expert for the indicator $i$. 


\subsubsection{Association rules}

The association rules can mine data to discover the frequency of the common occurrences of items in the data (Agrawal et al., 1993). The data are derived from different kinds of information. Even if the data are not substantial, the correlations between the data can still be concluded. Association rules were first used in the U.S. market for the association of goods purchased by customers and to determine the arrangement of the goods; therefore, it is also known as a market basket analysis (Ting et al., 2018). This method analyzes purchasing habits of customers by finding the association between the different goods that have been purchased. When this method is implemented, it is necessary to set the minimum support and minimum confidence, and extract the item collections in line with the setting, to obtain the rules that are in line with the objectives. Support refers to the probability of a simultaneous occurrence of A and B in the same data (KamsuFoguem et al., 2013). For example, 20\% support means that the probability of the simultaneous occurrence of $\mathrm{A}$ and $\mathrm{B}$ in all the data is $20 \%$, while $80 \%$ confidence means that the probability of $\mathrm{B}$ appearing in the data of $\mathrm{A}$ is $80 \%$.

\subsubsection{Artificial Neural Network (ANN)}

The ANN model, which imitates the operation of a biological neuronal network by connecting and storing learned knowledge in neurons, is an information-processing technique that was developed according to brain and neuronal system studies (Adeli \& Wu, 1998; Ling \& Liu, 2004). The potential of ANN as an effective prediction tool has been demonstrated in many prior studies. When compared with conventional statistical methods, the ANN model can be applied to construct nonlinear models, to produce accurate output values, and even to accept the input values of different types, or unknown variables (Juan et al., 2017). In this study, a Back-Propagation (BP) learning algorithm, featuring a multilayer, feed-forward neural network architecture was adopted to construct the ANN model, using STATISTICA software. Due to its efficiency and potential to improve the performance of neural networks, as well as its ability to enhance the accuracy of the model prediction, BP was used as the primary method for operating the ANN model.

\subsection{Results and validation}

\subsection{Cases}

This study collected the cases of school building projects from 2009 to 2019. The samples were selected, based on the following three principles: 1) preference was given to the building projects of teaching or administration buildings on university campuses (the number of these two types of building projects accounts for $75.8 \%$ of all new construction projects on MOE database); 2) any building project with a procurement cost that is larger than is stipulated in the Government Procurement Act (more than NTD 200 million); and 3) any case with a high data in- tegrity. Public school building projects from K-12 (kindergarten through to Twelfth Grade) were excluded because the supervision and provision of budgets for these projects were implemented by the local government, instead of the MOE. Therefore, there were a total of 62 samples that were distributed in all regions of Taiwan, which is consistent with the conditions of the three principles. According to the statistics, only 18 of the 62 cases were completed as scheduled, and the remaining 44 projects were delayed by an average of 299 days. In addition, only 12 of the 62 cases were completed within the budget, and the remaining 50 projects required an average supplemental appropriation of NTD 29.3 million (see Appendix 1). Apparently, the performance of PSBPs was generally poor in the past.

\subsection{Result analysis of FDM}

In this study, 18 experts, including three governmental officers in building project management, five facility managers (the Dean of General Affairs, and Professors) in the selected benchmarking universities, five architects, and five representatives of construction firms, were invited to carry out the FDM operation. They were experienced in public construction practice and had been engaged in school building projects for at least 16 years.

An FDM questionnaire was used for the factor selection, and 0 to 10 points were given, based on the evaluation of the degree of influence of all factors on the project execution. The statistical results are shown in Table 2. Finally, a total of 11 influencing factors in the planning and design and bid-inviting phases, and 10 influencing factors in the construction stage, were obtained as the important factors for the references of association rules and neural network models in the next phase, while any factor with an expert consensus value lower than a threshold of 5.48 (the consensus been accepted by $90 \%$ of experts) was deleted. According to the results, in the planning and design and bid-inviting phases, the important factors (each with an expert consensus value of greater than 7) were as follows: unreasonable budgeting, the low unit price of the work items, and a change in the owner's demands. In the construction stage, the important factors (each with an expert consensus value of greater than 7) were as follows: a labor shortage in the market, special materials or construction methods, the firm's poor contracting performance, shutdown and termination, frequent construction design changes, the firm's poor ability to fulfill contracts, and the firm's poor financial condition.

\subsection{Result analysis of association rules}

This study further explored the correlation of the identified negative factors and found the rules that influenced a project's performance. Sixty-two PSBPs were collected for the association rules analysis of data mining. The related variables and data types are described in Table 3.

The number of association rules and the usefulness of the mining results vary with the thresholds for support and confidence, both of which are user-defined. 
Table 2. FDM operating factors

\begin{tabular}{|c|c|c|c|c|c|c|c|}
\hline \multirow[t]{2}{*}{$\begin{array}{l}\text { Evaluation } \\
\text { factors }\end{array}$} & \multicolumn{2}{|c|}{$\begin{array}{c}\text { Most } \\
\text { conservative } \\
\text { value }\end{array}$} & \multicolumn{2}{|c|}{$\begin{array}{c}\text { Most } \\
\text { optimistic } \\
\text { value }\end{array}$} & \multicolumn{2}{|c|}{$\begin{array}{c}\text { Geometric } \\
\text { mean }\end{array}$} & \multirow{2}{*}{$\begin{array}{c}\text { Expert } \\
\text { consensus } \\
\text { value } G^{i}\end{array}$} \\
\hline & $\mathrm{CL}$ & $\mathrm{CU}$ & $\mathrm{OL}$ & $\mathrm{OU}$ & $\mathrm{CM}$ & $\mathrm{OM}$ & \\
\hline 1. HF_1 & 3 & 8 & 6 & 10 & 5.78 & 8.35 & $7.03^{\star}$ \\
\hline 2. PM_1 & 2 & 8 & 5 & 10 & 5.56 & 7.90 & $6.63^{*}$ \\
\hline 3. PM_2 & 3 & 8 & 6 & 10 & 5.81 & 8.13 & $6.99^{*}$ \\
\hline 4. PF_1 & 2 & 7 & 4 & 9 & 4.09 & 6.40 & 5.36 \\
\hline 5. HF_2 & 1 & 8 & 4 & 10 & 4.94 & 7.31 & $6.08^{\star}$ \\
\hline 6. PF_2 & 1 & 7 & 3 & 9 & 4.60 & 6.89 & 5.47 \\
\hline 7. PF_3 & 1 & 6 & 3 & 9 & 3.78 & 6.37 & 4.81 \\
\hline 8. PP_1 & 2 & 8 & 4 & 10 & 5.54 & 7.68 & $6.40^{*}$ \\
\hline 9. PP_2 & 3 & 8 & 5 & 10 & 5.50 & 7.69 & $6.55^{\star}$ \\
\hline 10. PM_3 & 1 & 8 & 3 & 10 & 4.49 & 6.99 & $5.66^{*}$ \\
\hline 11. PM_4 & 1 & 8 & 3 & 10 & 4.49 & 6.99 & $5.66^{*}$ \\
\hline 12. PP_3 & 3 & 8 & 6 & 10 & 6.18 & 8.45 & $7.15^{\star}$ \\
\hline 13. PP_4 & 1 & 8 & 5 & 10 & 4.96 & 7.39 & $6.32^{\star}$ \\
\hline 14. PP_5 & 3 & 8 & 6 & 10 & 6.48 & 8.62 & $7.27^{\star}$ \\
\hline 15. PM_5 & 1 & 7 & 3 & 10 & 3.75 & 6.40 & 5.05 \\
\hline 16. EE_1 & 0 & 7 & 2 & 9 & 0 & 5.94 & 3.80 \\
\hline 17. HF_3 & 5 & 8 & 7 & 10 & 6.21 & 8.56 & $7.47^{\star}$ \\
\hline 18. HF_4 & 4 & 8 & 6 & 10 & 6.51 & 8.67 & $7.28^{\star}$ \\
\hline 19. HF_5 & 4 & 8 & 6 & 10 & 6.20 & 8.52 & $7.17^{\star}$ \\
\hline 20. PF_4 & 2 & 8 & 5 & 10 & 5.25 & 7.65 & $6.47^{\star}$ \\
\hline 21. PP_6 & 1 & 7 & 3 & 10 & 4.25 & 6.86 & 5.34 \\
\hline 22. PP_7 & 4 & 8 & 7 & 10 & 5.73 & 8.05 & $7.32^{\star}$ \\
\hline 23. PP_8 & 1 & 7 & 3 & 9 & 3.78 & 6.29 & 5.02 \\
\hline 24. PP_9 & 3 & 8 & 7 & 10 & 6.20 & 8.60 & $7.47^{\star}$ \\
\hline 25. PF_5 & 0 & 7 & 3 & 9 & 0 & 6.64 & 4.37 \\
\hline 26. PM_6 & 1 & 8 & 5 & 10 & 4.07 & 6.73 & $5.92^{\star}$ \\
\hline 27. PM_7 & 1 & 7 & 3 & 10 & 4.07 & 6.75 & 5.25 \\
\hline 28. EE_2 & 1 & 8 & 3 & 10 & 3.69 & 6.31 & 5.17 \\
\hline 29. PF_6 & 1 & 8 & 3 & 10 & 4.98 & 7.51 & $5.99^{\star}$ \\
\hline 30. EE_3 & 0 & 8 & 3 & 10 & 0 & 7.50 & 4.80 \\
\hline 31. PP_10 & 1 & 6 & 3 & 8 & 3.40 & 5.73 & 4.54 \\
\hline 32. PP_11 & 1 & 7 & 3 & 9 & 3.54 & 6.01 & 4.86 \\
\hline 33. EE_4 & 4 & 8 & 6 & 10 & 6.04 & 8.30 & $8.30^{*}$ \\
\hline 34. PM_8 & 3 & 7 & 5 & 10 & 5.17 & 7.57 & $7.57^{\star}$ \\
\hline 35. PP_12 & 1 & 7 & 3 & 10 & 3.98 & 6.50 & 5.15 \\
\hline 36. EE_5 & 1 & 7 & 3 & 10 & 4.02 & 6.56 & 5.18 \\
\hline
\end{tabular}

Note: The average of $G^{i}$ is 6.09. The adjusted threshold $G^{i}$ is set 5.48 denoting the consensus has been accepted by $90 \%$ of experts. * represents any factor that is reserved, due to achieving the expert consensus threshold.

If the threshold is set too high, some useful patterns will be reduced. However, determining the appropriate minimum support and confidence values is a subtle task (Telikani et al., 2020). Some studies indicated that the settings for appropriate support and confidence values is often a matter of trial and error, and users may specify
Table 3. The setting of the association rules parameters for the critical factors influencing project performance

\begin{tabular}{|c|c|c|}
\hline Phase & Variable & Data type and definition \\
\hline \multirow{11}{*}{ 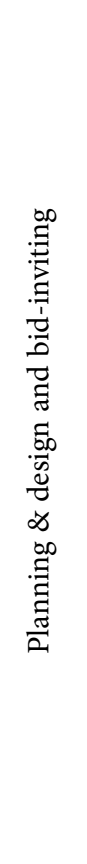 } & HF_1 & None; low; medium; high \\
\hline & PM_1 & Without influence; with influence \\
\hline & PM_2 & $\begin{array}{l}\text { Proportion of the days added to the } \\
\text { examination in the original project } \\
\text { duration: none; low; medium; high }\end{array}$ \\
\hline & HF_2 & Good; acceptable; poor \\
\hline & PP_1 & None; low; medium; high \\
\hline & PP_2 & $\begin{array}{l}\text { High integrity and no design time } \\
\text { increasing; non-integrity and design } \\
\text { time increasing }\end{array}$ \\
\hline & PM_3 & $\begin{array}{l}\text { Traditional design-bid-build; design- } \\
\text { build }\end{array}$ \\
\hline & PM_4 & $\begin{array}{l}\text { Economically most advantageous } \\
\text { tender; lowest tender; minimum bid } \\
\text { with qualified scores }\end{array}$ \\
\hline & PP_3 & $\begin{array}{l}\text { Counted, based on the number of bid } \\
\text { rejections: none; low; medium; high }\end{array}$ \\
\hline & PP_4 & $\begin{array}{l}\text { Counted, based on contract periods } \\
\text { (days): low; medium; high }\end{array}$ \\
\hline & PP_5 & $\begin{array}{l}\text { Counted, based on contract amount } \\
\text { (NTD } 100 \text { million): low; medium; high }\end{array}$ \\
\hline \multirow{10}{*}{ 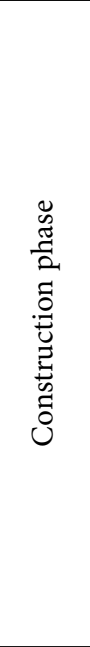 } & HF_3 & $\begin{array}{l}\text { The proportion of the firm's capital in } \\
\text { the total project fund: poor; acceptable; } \\
\text { good }\end{array}$ \\
\hline & HF_4 & Good; acceptable; poor \\
\hline & HF_5 & Without abnormity; with abnormity \\
\hline & PF_4 & $\begin{array}{l}\text { Low complexity without influence on } \\
\text { the schedule; high complexity, with an } \\
\text { influence on the schedule }\end{array}$ \\
\hline & PP_7 & $\begin{array}{l}\text { Counted, based on the number of times: } \\
\text { none; low; medium; high }\end{array}$ \\
\hline & PP_9 & No; yes \\
\hline & PM_6 & Without delays; with delays \\
\hline & PF_6 & No; yes \\
\hline & EE_4 & No; yes \\
\hline & PM_8 & No; yes \\
\hline \multirow{2}{*}{ 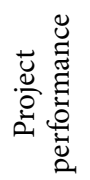 } & $\begin{array}{l}\text { Schedule } \\
\text { variability }\end{array}$ & $\begin{array}{l}\text { Categorical variable: excellent; good; } \\
\text { poor; bad }\end{array}$ \\
\hline & $\begin{array}{l}\text { Cost } \\
\text { variability }\end{array}$ & $\begin{array}{l}\text { Categorical variable: excellent; good; } \\
\text { poor; bad }\end{array}$ \\
\hline
\end{tabular}

the minimum support and minimum confidence to their preferences (Olafsson et al., 2008; Mansingh et al., 2011). For example, Liu et al. (2000) proposed the subjective and objective analysis of interestingness to find interesting and useful rules. Hence, by referring to the thresholds set in literature, this study set the thresholds in the planning and design, bid-inviting, and construction phases as a minimum support of $40 \%$ and a minimum confidence of $90 \%$.

Support and confidence are often used to determine whether a rule is statistically significant. Lift is used to measure the dependence and correlation between an antecedent and a consequent. If the lift is one, it indicates that 
the antecedent and the consequent are independent, so the knowledge discovered is worthless. A lift greater than one indicates a positive correlation, which means that the consequence is absolutely influenced by the occurrence of the antecedent. Hence, based on the association rules analysis in this study, those with lifts greater than one were classified as the rules with a significant causal association.

Taking the influencing consequent as the project performance (poor cost and project duration) as an example, this study finally obtained 12 rules for the planning and design and bid-inviting phases, and nine rules for the con- struction stage (Table 4). Support is used to measure the probability that Item A (Antecedent) and Item B (Consequent) occur together, namely, the proportion of the rule in the record of all item factors. The results showed that some items often occurred together, which indicated that the support of this rule was high and the school project managers should pay more attention to it. For example, in the critical factors influencing planning and design and bid-inviting phases of building projects, the proportion of "acceptable ability and experience of the planning and design unit" and "the use of traditional contracting method

Table 4. Association rule results of factors influencing the building project's performance in the planning and design, bid-inviting, and construction phases

\begin{tabular}{|c|c|c|c|c|c|c|}
\hline Phase & Rule & Antecedent & Consequent & Support & Confidence & Lift \\
\hline \multirow{12}{*}{ 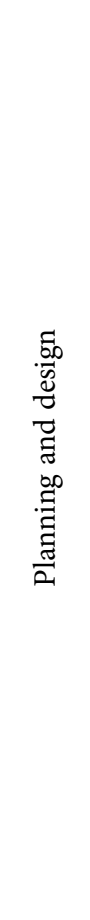 } & $\mathrm{R} 1$ & Long project duration, low contract amount & High cost & 41.935 & 100.000 & 1.240 \\
\hline & $\mathrm{R} 2$ & $\begin{array}{l}\text { Influence of pre-work on schedule, acceptable ability and } \\
\text { experience of the planning and design unit }\end{array}$ & $\begin{array}{l}\text { Long project } \\
\text { duration, high cost }\end{array}$ & 41.935 & 100.000 & 1.409 \\
\hline & $\mathrm{R} 3$ & Long project duration, traditional procurement, minimum bid & High cost & 54.838 & 100.000 & 1.240 \\
\hline & $\mathrm{R} 4$ & $\begin{array}{l}\text { Traditional procurement, incomplete design drawing } \\
\text { explanations, increased design time }\end{array}$ & $\begin{array}{l}\text { Long project } \\
\text { duration, high cost }\end{array}$ & 40.322 & 100.000 & 1.409 \\
\hline & R5 & $\begin{array}{l}\text { Long project duration, traditional procurement, low contract } \\
\text { amount }\end{array}$ & High cost & 41.935 & 100.000 & 1.240 \\
\hline & R6 & $\begin{array}{l}\text { Traditional procurement, influence of pre-work on schedule, } \\
\text { acceptable ability and experience of the planning and design unit }\end{array}$ & $\begin{array}{l}\text { Long project } \\
\text { duration, high cost }\end{array}$ & 40.322 & 100.000 & 1.409 \\
\hline & R7 & $\begin{array}{l}\text { Traditional procurement, acceptable ability and experience of the } \\
\text { planning and design unit }\end{array}$ & High cost & 66.129 & 100.000 & 1.240 \\
\hline & $\mathrm{R} 8$ & $\begin{array}{l}\text { Traditional procurement, acceptable ability and experience of the } \\
\text { planning and design unit, minimum bid }\end{array}$ & High cost & 53.225 & 100.000 & 1.240 \\
\hline & R9 & $\begin{array}{l}\text { High cost, traditional procurement, influence of pre-work on } \\
\text { schedule }\end{array}$ & $\begin{array}{l}\text { Long project } \\
\text { duration }\end{array}$ & 46.774 & 96.666 & 1.362 \\
\hline & $\mathrm{R} 10$ & $\begin{array}{l}\text { Acceptable ability and experience of the planning and design } \\
\text { unit, minimum bid }\end{array}$ & $\begin{array}{l}\text { Long project } \\
\text { duration, high cost }\end{array}$ & 64.516 & 95.238 & 1.341 \\
\hline & $\mathrm{R} 11$ & $\begin{array}{l}\text { Traditional procurement, acceptable ability and experience of the } \\
\text { planning and design unit, minimum bid }\end{array}$ & $\begin{array}{l}\text { Long project } \\
\text { duration, high cost }\end{array}$ & 62.903 & 95.122 & 1.340 \\
\hline & $\mathrm{R} 12$ & $\begin{array}{l}\text { Traditional procurement, acceptable ability and experience of the } \\
\text { planning and design unit, minimum bid }\end{array}$ & $\begin{array}{l}\text { Long project } \\
\text { duration, high cost }\end{array}$ & 50.000 & 93.939 & 1.323 \\
\hline \multirow{9}{*}{ 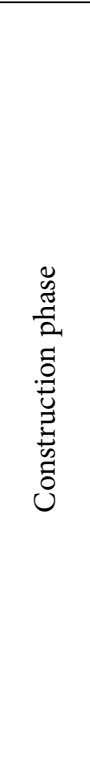 } & $\mathrm{R} 1$ & Firm's acceptable ability to fulfill contracts, delayed acceptance & $\begin{array}{l}\text { Long project } \\
\text { duration, high cost }\end{array}$ & 45.161 & 100.000 & 1.409 \\
\hline & $\mathrm{R} 2$ & Firm's poor contracting performance, delayed acceptance & $\begin{array}{l}\text { Long project } \\
\text { duration, high cost }\end{array}$ & 40.322 & 100.000 & 1.409 \\
\hline & $\mathrm{R} 3$ & $\begin{array}{l}\text { High cost, firm's poor contracting performance, firm's acceptable } \\
\text { ability to fulfill contracts }\end{array}$ & $\begin{array}{l}\text { Long project } \\
\text { duration }\end{array}$ & 53.225 & 100.000 & 1.409 \\
\hline & $\mathrm{R} 4$ & $\begin{array}{l}\text { Long project duration, firm's poor contracting performance, } \\
\text { firm's acceptable ability to fulfill contracts }\end{array}$ & High cost & 53.225 & 100.000 & 1.240 \\
\hline & R5 & $\begin{array}{l}\text { Firm's poor contracting performance, firm's acceptable ability to } \\
\text { fulfill contracts, delayed acceptance }\end{array}$ & $\begin{array}{l}\text { Long project } \\
\text { duration, high cost }\end{array}$ & 40.322 & 100.000 & 1.409 \\
\hline & R6 & $\begin{array}{l}\text { Labor shortage in the market, firm's acceptable ability to fulfill } \\
\text { contracts }\end{array}$ & $\begin{array}{l}\text { Long project } \\
\text { duration, high cost }\end{array}$ & 50.000 & 100.000 & 1.409 \\
\hline & R7 & $\begin{array}{l}\text { Labor shortage in the market, firm's poor contracting } \\
\text { performance }\end{array}$ & $\begin{array}{l}\text { Long project } \\
\text { duration, high cost }\end{array}$ & 40.322 & 100.000 & 1.409 \\
\hline & $\mathrm{R} 8$ & Firm's acceptable ability to fulfill contracts & $\begin{array}{l}\text { Long project } \\
\text { duration, high cost }\end{array}$ & 66.129 & 97.619 & 1.375 \\
\hline & R9 & $\begin{array}{l}\text { Firm's acceptable ability to fulfill contracts, occurrence of } \\
\text { shutdown and termination, increased project duration, firm's } \\
\text { poor contracting performance }\end{array}$ & $\begin{array}{l}\text { Long project } \\
\text { duration, high cost }\end{array}$ & 41.935 & 96.296 & 1.421 \\
\hline
\end{tabular}


(design-bid-build)" always led to poor performance (with the support of more than 60\%). The "lowest tender" was also an important factor (with the support of more than $50 \%)$. In the critical factors influencing the construction phase of building projects, the proportion of "the firm's acceptable ability to fulfill contracts", "the firm's poor contracting performance", and "a labor shortage in the market" always led to poor performance (with the support of more than $50 \%$ ).

\subsection{Result analysis of ANN}

In order to accurately predict the future performance of projects and achieve early warning, this study adopted ANN to establish a prediction model. The establishment of a neural network model consists of the following phases: sample processing, training and testing, and result judgment. During the sample processing in this study, the 21 critical factors selected by FDM were taken as the independent variable ( $X$ value), and the project schedule and cost variability of project performance were taken as the dependent variable ( $Y$ value). The overall variable settings are shown in Table 5. The project schedule and cost variability are calculated according to Eqns (5) and (6):
Schedule variability $(\%)=$

[(actual completion period -

original project duration) /

original project duration $]^{\star} 100$;

Cost variability $(\%)=$

[(settlement amount -

bid-awarding amount) /

bid-awarding amount $]^{\star} 100$.

In this study, the training and testing cases were randomly selected from the 62 cases. 43 (70\%) were randomly selected for training and $19(30 \%)$ for testing to predict the project duration and cost variability. Multilayer perceptron (MLP) models were generated and implemented using the ANN model provided in the STATISTICA software. MLP networks were constructed using the Automated Network Search (ANS) approach for creating predictive models of STATISTICA. The best five MLP networks were retained by ANS, trying different numbers of hidden units (1-15), input/output activation functions, and training algorithms. Further, the best five MLP networks were determined using the ANS (see Appendix 2). Their accuracy rate results on training and testing are summarized in Table 6 .

Table 5. Variable definitions of ANN

\begin{tabular}{|c|c|c|}
\hline Phase & Variable & Data definition \\
\hline \multirow{11}{*}{ 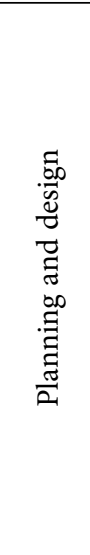 } & HF_1 & Counted, based on the number of times; none $=0 ;$ low $=1 ;$ medium $=2-5 ;$ high $=$ above 5 \\
\hline & PM_1 & Without influence $=0$; with influence $=1$ \\
\hline & PM_2 & $\begin{array}{l}\text { Proportion of the days added to the examination in the original project duration; none }=0 \text {; low }=0.1-0.5 \text {; } \\
\text { medium }=0.5-0.9 ; \text { high }=\text { above } 1\end{array}$ \\
\hline & HF_2 & Good $=$ more than 80 points; acceptable $=70-79$ points; poor $=$ less than 69 points \\
\hline & PP_1 & Counted based on the number of times; none $=0$; low $=1$; medium $=2$; high $=$ above 3 \\
\hline & PP_2 & High integrity and no design time increasing $=0$; non-integrity and design time increasing $=1$ \\
\hline & PM_3 & Traditional design-bid-build $=1$; design-build $=2$ \\
\hline & PM_4 & Economically most advantageous tender $=1$; lowest tender $=2 ;$ minimum bid with qualified scores $=3$ \\
\hline & PP_3 & Counted, based on the number of bid rejections: none $=0$; low $=1$; medium $=2$; high $=3$ \\
\hline & PP_4 & Counted, based on contract periods (days): low $=360-685 ;$ medium $=686-1010 ;$ high $=$ above 1010 \\
\hline & PP_5 & Counted, based on contract amount (NTD 100 million): low = below 4; medium $=4.1-8.9 ;$ high $=$ above 9 \\
\hline \multirow{10}{*}{ 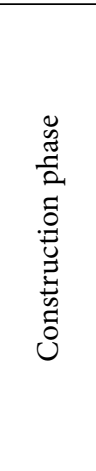 } & HF_3 & Proportion of the firm's capital in the total project fund: poor $=$ below 0.5 ; acceptable $=0.6-1$; good above $=1$ \\
\hline & HF_4 & Good $=$ more than 80 points; acceptable $=70-79$ points; poor $=$ less than 69 points \\
\hline & HF_5 & Without abnormity $=0$; with abnormity $=1$ \\
\hline & PF_4 & Low complexity without influence on the schedule $=0$; high complexity with influence on the schedule $=1$ \\
\hline & PP_7 & Counted based on the number of times: none $=0 ;$ low $=1-3 ;$ medium $=4-5 ;$ high $=$ above 5 \\
\hline & PP_9 & No $=0$; yes $=1$ \\
\hline & PM_6 & Without delays $=0 ;$ with delays $=1$ \\
\hline & PF_6 & No $=0$; yes $=1$ \\
\hline & EE_4 & No $=0 ;$ yes $=1$ \\
\hline & PM_8 & No $=0$; yes $=1$ \\
\hline \multirow{2}{*}{ 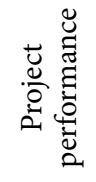 } & $\begin{array}{l}\text { Schedule } \\
\text { variability }\end{array}$ & $\begin{array}{l}\text { Excellent }=\text { above }-11 \% \text { (earlier completion); good }=0 \sim-10 \% \text { (completion on schedule); poor }=1 \sim 10 \% \\
\text { (delay); bad = above } 11 \% \text { (serious delay) }\end{array}$ \\
\hline & $\begin{array}{l}\text { Cost } \\
\text { variability }\end{array}$ & Excellent $=$ above $-11 \%$; good $=0 \sim-10 \%$; poor $=1 \sim 10 \%$; bad $=$ above $11 \%$ \\
\hline
\end{tabular}


Table 6. Test results of neural network prediction

\begin{tabular}{|c|c|c|c|c|c|}
\hline \multicolumn{3}{|c|}{$\begin{array}{c}\text { Planning \& design and bid-inviting phases: accuracy rate of } \\
\text { schedule variability prediction }\end{array}$} & \multicolumn{3}{|c|}{$\begin{array}{c}\text { Planning \& design and bid-inviting phases: accuracy rate of cost } \\
\text { variability prediction }\end{array}$} \\
\hline Mode & Train & Test & Mode & Train & Test \\
\hline MLP 17-8-4 & $83.72 \%$ & $84.21 \%$ & MLP 17-7-3 & $100.00 \%$ & $73.68 \%$ \\
\hline MLP 17-9-4 & $86.05 \%$ & $84.21 \%$ & MLP 17-8-3 & $95.35 \%$ & $84.21 \%$ \\
\hline MLP 17-7-4 & $97.67 \%$ & $84.21 \%$ & MLP 17-13-3 & $93.02 \%$ & $84.21 \%$ \\
\hline MLP 17-11-4 & $90.70 \%$ & $84.21 \%$ & MLP 17-11-3 & $95.35 \%$ & $73.68 \%$ \\
\hline MLP 17-10-4 & $81.40 \%$ & $78.95 \%$ & MLP 17-6-3 & $93.02 \%$ & $73.68 \%$ \\
\hline \multicolumn{3}{|c|}{$\begin{array}{c}\text { Construction phase: accuracy rate of schedule variability } \\
\text { prediction }\end{array}$} & \multicolumn{3}{|c|}{ Construction phase: accuracy rate of cost variability prediction } \\
\hline Mode & Train & Test & Mode & Train & Test \\
\hline MLP 18-10-4 & $90.70 \%$ & $84.21 \%$ & MLP 18-10-3 & $83.72 \%$ & $84.21 \%$ \\
\hline MLP 18-13-4 & $90.70 \%$ & $84.21 \%$ & MLP 18-7-3 & $51.16 \%$ & $84.21 \%$ \\
\hline MLP 18-12-4 & $86.05 \%$ & $84.21 \%$ & MLP 18-6-3 & $81.40 \%$ & $73.68 \%$ \\
\hline MLP 18-9-4 & $90.70 \%$ & $84.21 \%$ & MLP 18-9-3 & $79.07 \%$ & $73.68 \%$ \\
\hline MLP 18-6-4 & $95.35 \%$ & $84.21 \%$ & MLP 18-8-3 & $76.74 \%$ & $73.68 \%$ \\
\hline
\end{tabular}

Note: MLP represents "Multilayer perceptron", which is a class of feed-forward ANN. The three values of MLP denote the number of neurons of an input layer, a hidden layer, and an output layer, respectively.
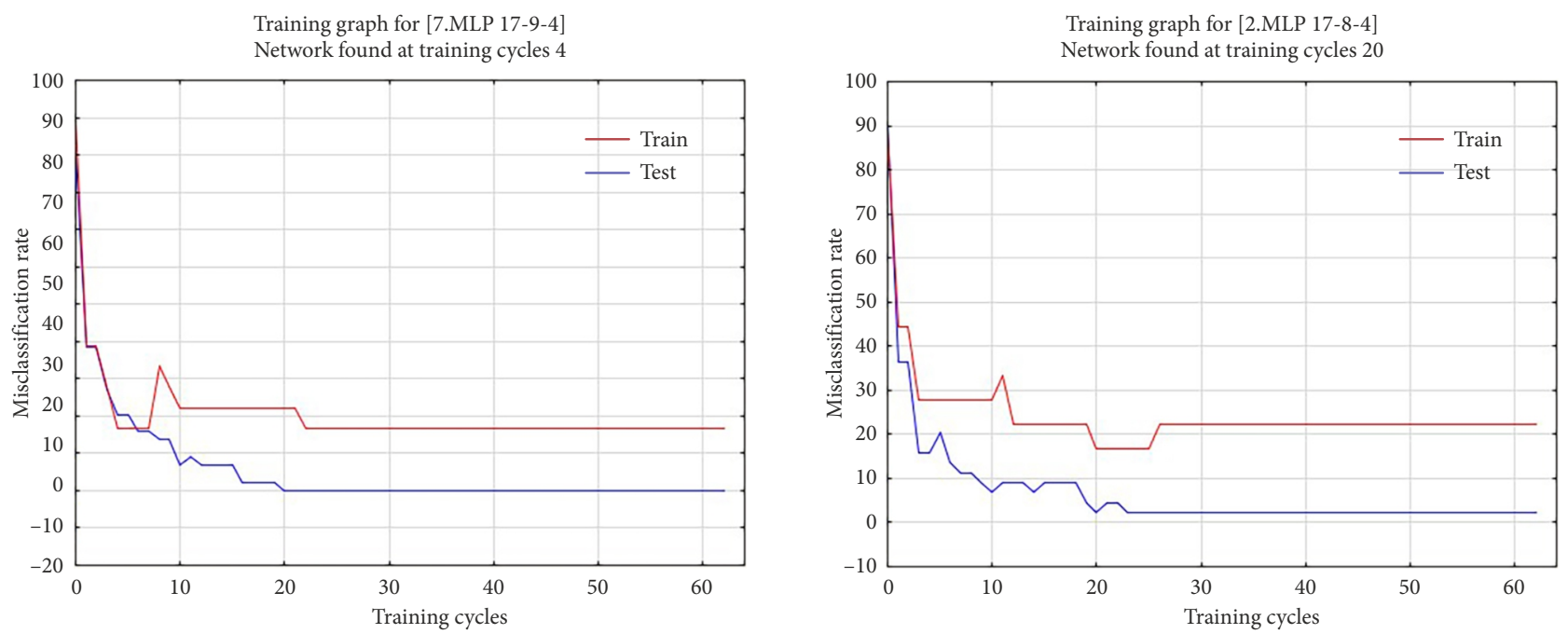

Figure 3. Convergence results of the cases for neural network training and testing (taking the schedule prediction in the planning and design, bid-inviting, and construction phases as an example)

The convergence results of the cases for neural network training and testing are shown in Figure 3. According to Table 6, in the planning and design, bid-inviting, and construction phases, the prediction model established in this study has an optimal accuracy of $84.21 \%$ for the cost and project schedule variability of the test cases. This indicates a certain referential value and can be used in the future for the performance evaluation of the initial project management and the phased early warning during project execution.

\section{Discussion}

In terms of the application of association rules, many factors in the rules are highly repetitive. For example, in the construction stage, the firm's contracting performance and ability to fulfill a contract are highly critical factors. In other words, during a building project, if a school encounters the situation where the construction unit is closed due to financial crisis, or it terminates the contract because of a shutdown, the subsequent administrative procedures will be quite complex and contract disputes will easily arise during the project execution, resulting in the extension of the project, as well as cost increases. This finding is consistent with the view of Ibbs et al. (2011). In addition, the information mined from the association rules in this study showed that many factors were, to some extent, related to the "contractor selection mechanism", notwithstanding the planning and design and bid-inviting phases, or the construction phase. This indicates that good firms could reduce the subsequent contract disputes for the owners. The virtuous cycle was adopted to improve the 
competitiveness of good firms and to reduce the price-cutting competition of bad firms, so as to improve the overall construction quality and satisfaction. This argument echoed the viewpoint of Flanagan et al. (2006). However, the traditional procurement mode (design-bid-build) and the lowest tender have a negative influence on the project performance and satisfaction (Hardie \& Saha, 2009). This is why the Taiwanese government has strongly promoted the design-build method and the policy of the most economically-advantageous tender in recent years (Perng et al., 2006). This is also closer to the trend of procurement and project delivery in the international construction industry (Sullivan et al., 2017).

In terms of neural network prediction, regardless of the events or occurrences in the planning and design phase, or in the construction phase, the prediction accuracy of the model reached up to $84 \%$ for the cost and schedule variability. Generally-speaking, the procurement process for public school works consists of the following phases: planning and design, bid-inviting, construction, and maintenance management. However, many studies pointed out that investing more resources at the beginning of a project, in order to control the variations, has a great influence on the future performance of the project (Wang et al., 2012). As shown in Figure 4, there are currently only two inspection points for MOE to conduct building project performance management: the project progress reaches $30 \%$ of the planning and design phase (first inspection), and the progress reaches $30 \%$ of the construction phase (second inspection). Considering the complexity and variations of the projects, there is an urgent need to establish more inspection points, based on the proposed prediction model. For example, it is suggested that, with the help of the findings of this study, at least five inspection points could be identified for project controlling and management. In the future, if the government can effectively make predictions during the procurement of public works for early prevention and putting forward solutions, government funds will be significantly saved, and projects extensions could be averted.
- Pre-project inspection: MOE can analyze the potential risks and make performance predictions before the project is initiated, based on the owner's demands, the pre-work of the project, and the construction license examination procedures.

- Project Inspection I: the same procedure with the current inspection point when the project progress reaches $30 \%$ of the planning and design phase.

- Pre-bid inspection: the MOE can review the project outcome of the planning and design phase and make performance predictions, based on the procurement and bid-inviting methods, the bid-awarding methods, the unit price of work items, the project duration, and the budgeting.

- Pre-construction inspection: the MOE can evaluate the contractors' performance, the ability to fulfill contracts, as well as the financial conditions for analyzing the potential risks and making performance predictions before construction.

- Project Inspection II: the same procedure as the current inspection point, when the project progress reaches $30 \%$ of the construction phase.

In this study, the experts who were interviewed summarized the reasons for the poor performance of $21 \mathrm{criti}-$ cal factors in a project's performance. They made suggestions on how the project performance can be improved and also posited some key management strategies for this to occur. These are shown in Table 7. Their suggestions can be provided to competent authorities (owners) in the future, as well as design and construction units, in order to improve the performance satisfaction of public projects.

Compared to previous studies in which the prediction models can only be applied to the single stage of the building life cycle or the onefold dimension of project performance (Al-Momani, 1996; Aretoulis et al., 2006; Aretoulis, 2019; Armaghani et al., 2017; Chen \& Huang, 2006; Wang et al., 2012), the three-phased research process of this study was used to successfully develop more factors that might influence project performance prediction to
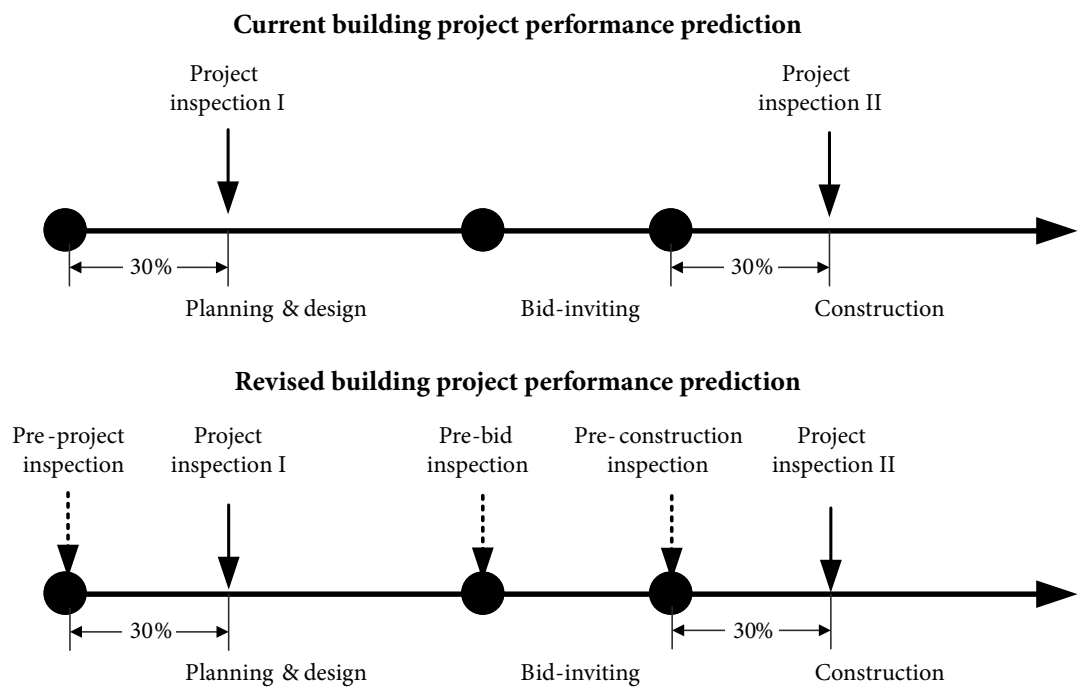

Figure 4. Potential mechanism of project performance management 
Table 7. Suggestions for project performance improvement

\begin{tabular}{|c|c|c|}
\hline Phase & Variable & Reasons for poor project performance and improvement suggestions \\
\hline \multirow{11}{*}{ 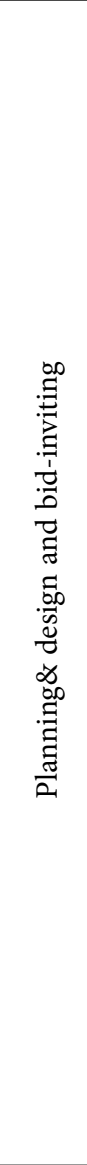 } & HF_1 & $\begin{array}{l}\text { The owner often changes design due to the demand changes, and consequently, the design cannot be finalized. It } \\
\text { is suggested that, in the future, the owner should integrate the same demands of all the users in advance, to avoid } \\
\text { excessive design. }\end{array}$ \\
\hline & PM_1 & $\begin{array}{l}\text { Pre-works include land acquisition, urban change, water and land conservation, tree protection, and environmental } \\
\text { impact assessments. It is suggested that the owner should strengthen the pre-work milestone control. }\end{array}$ \\
\hline & PM_2 & $\begin{array}{l}\text { Examination operations include building permits and regulations. The administrative costs will increase if the } \\
\text { procedure fails to be completed as scheduled. It is suggested that the owner should complete the procedure prior } \\
\text { to the planning and design. }\end{array}$ \\
\hline & HF_2 & $\begin{array}{l}\text { If there is poor planning and design, or lack of experience, it leads to missing items in the design and errors } \\
\text { in the quantity calculation, the design will be changed, and the costs will increase. The review items of the } \\
\text { "selection mechanism" should be specified when selecting architects for the design unit. }\end{array}$ \\
\hline & PP_1 & $\begin{array}{l}\text { Frequently-changed owner demands, inexperienced architects, or special circumstances, result in design changes. } \\
\text { The designer's responsibilities should be specified in the bid-inviting documents. }\end{array}$ \\
\hline & PP_2 & $\begin{array}{l}\text { The incomplete review of drawings, or the poor constructability of a design, leads to an increase in the project's } \\
\text { duration and costs. It is suggested that the contract should be drawn up and the design responsibilities should be } \\
\text { investigated. }\end{array}$ \\
\hline & PM_3 & $\begin{array}{l}\text { In the traditional design-bid-build procurement mode, project interfaces, communication, and coordination will } \\
\text { increase, which will easily influence the project schedule or cost. It is suggested that bid-inviting strategies are } \\
\text { carefully selected according to project attributes, to reduce the disputes arising from the contract management } \\
\text { and the execution. }\end{array}$ \\
\hline & PM_4 & $\begin{array}{l}\text { Different bid-awarding methods influence a firm's profits, long-term competitiveness, and costs. It is suggested } \\
\text { that the bid-awarding method is selected according to the project's attributes, in order to reduce the risk. }\end{array}$ \\
\hline & PP_3 & $\begin{array}{l}\text { Inconsistency between the unit price budgets of the work items and the market conditions, and the unreasonable } \\
\text { estimation of building materials and prices, has led to many bid failures and rejections. It is suggested that the designer } \\
\text { should provide inquiry information and analyze the reasonability of the unit price budgets of all the work items. }\end{array}$ \\
\hline & $P P \_4$ & $\begin{array}{l}\text { Insufficient consideration regarding the design or temporary conditions leads to the project duration being } \\
\text { constantly extended in the construction phase. It is suggested that the design unit should propose a reasonable } \\
\text { project duration analysis in the planning and design. }\end{array}$ \\
\hline & PP_5 & $\begin{array}{l}\text { The construction budget is too low. This may affect the bidding intention of a firm, so that the project cannot be } \\
\text { contracted. It is recommended that it should be a budget that has a reasonable profit, according to the market } \\
\text { situation, and that the budget should be reviewed for any design omission or defect. }\end{array}$ \\
\hline \multirow{10}{*}{ 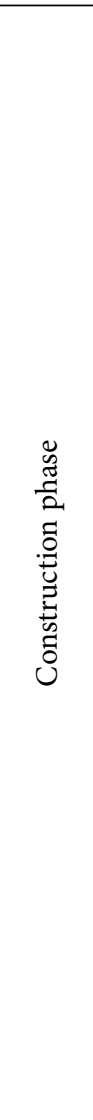 } & HF_3 & $\begin{array}{l}\text { If the construction unit lacks a project contracting performance or experience, it will affect the execution of the } \\
\text { project. It is suggested that the qualification conditions for selecting construction units should be specified, and } \\
\text { that they must have experience in contracting school building projects. }\end{array}$ \\
\hline & HF_4 & $\begin{array}{l}\text { If the construction unit fails to fulfill the contract, due to poor construction management, the costs and project } \\
\text { duration will be increased. It is suggested that the selection mechanism and scoring standards should be specified. }\end{array}$ \\
\hline & HF_5 & $\begin{array}{l}\text { The construction unit is in a poor financial condition, unable to pay its subcontractors, and may have to close. It } \\
\text { is suggested that the firm's financial situation should be included in the selection and evaluation mechanism. }\end{array}$ \\
\hline & PF_4 & $\begin{array}{l}\text { The project interface includes civil, architectural, and electromechanical integration, and poor cross-functional } \\
\text { coordination and communication will influence the project's progress and performance. It is suggested that the } \\
\text { interface coordination and integration should be allocated to a Professional Construction Management (PCM) team. }\end{array}$ \\
\hline & PP_7 & $\begin{array}{l}\text { During the construction, the design is often changed in the construction phase, due to policy changes, demand } \\
\text { changes, and differences in the site construction environment. It is suggested that a complete and practical } \\
\text { construction plan is drawn up to deal with various emergencies in the construction. }\end{array}$ \\
\hline & PP_9 & $\begin{array}{l}\text { The construction may be forced to stop in the case of geological conditions, the inclination of adjacent houses, } \\
\text { or unexpected conditions. It is suggested that detailed plans are made in the pre-work stage to establish an } \\
\text { information platform for the problems encountered in the project execution, and that the owner and the design } \\
\text { supervision unit should understand the concept of risk control. }\end{array}$ \\
\hline & PM_6 & $\begin{array}{l}\text { Due to the poor construction quality, the firm is required to improve in the acceptance phase, which incurs extra } \\
\text { costs. It is suggested that detailed acceptance standards and procedures are drawn up in the contract, and that a } \\
\text { joint inspection platform for acceptance is established to solve the problems in real time. }\end{array}$ \\
\hline & PF_6 & $\begin{array}{l}\text { The improper handling of personnel, equipment, or protection by the construction unit may lead to safety } \\
\text { incidents and may influence the completion schedule. It is suggested that the firm should be required to } \\
\text { strengthen the labor safety and health training education. }\end{array}$ \\
\hline & EE_4 & $\begin{array}{l}\text { A labor shortage within the firm seriously influences the completion of projects and produces related costs. It is } \\
\text { suggested that the resources and resource platforms are checked before construction, in order to understand the } \\
\text { condition of the human resources that have been established. }\end{array}$ \\
\hline & PM_8 & $\begin{array}{l}\text { If the design unit adopts special specifications or construction methods, the construction unit will be unable to } \\
\text { fulfill the contract and subsequent construction costs will be produced. It is suggested that the firm should be } \\
\text { required to draw up an alternative approach for the materials or construction methods, or carry out a project } \\
\text { engineering analysis. }\end{array}$ \\
\hline
\end{tabular}


improve the application on different stages of the building life cycle. However, considering the case acquisition of the database and the integrity of the project information, there are still some limitations of this study. Firstly, only PSBPs that comply with the Government Procurement Act of Taiwan are listed and analyzed; in other words, projects from private sectors and non-school building projects are not considered due to limited database access. Secondly, some PSBPs with incomplete data in the MOE database may be excluded from the sampling process. There is still room for enhancing the data quality (e.g., the comprehensive datamation of project documents and properties) and, therefore, for increasing the sample size to improve the prediction accuracy. Furthermore, this study focused on the evaluation of project performance in the planning and design, bid-inviting and construction phases. However, the performance evaluation of building projects in the subsequent phases of a project's lifecycle (such as its operation, maintenance, and management) is still important for the different stakeholders in a project. Extending the application of project performance prediction to other types of buildings and later stages of the building life cycle will continue to require attention in future studies.

\section{Conclusions and suggestions}

This study collected a total of 62 building projects from 2009 to 2019, and it was found that most projects had, in fact, lasted longer and cost more than their original targets (i.e. they performed poorly). In the past, the performance of building projects was mainly controlled by human experience and subjective judgments, as they lacked fair and objective prediction models. Taiwan has an average of over 900 public school building projects each year, with a total expenditure of NTD 30 billion. With such a huge market, it is urgent to establish a performance prediction system that can be used in the planning and design of building projects, as well as in the construction phase.

This study conducted a literature review and established that there are a total of 21 negative critical factors influencing the performance of school building projects. With expert interviews and FDM, this study obtained a total of 11 critical factors with a high-intensity correlation in planning, design and bid-inviting, as well as the construction phase, by using an association rules analysis, and it proposed the prevention and response strategies for these factors. The prediction model established by ANN has an accuracy rate of $84.21 \%$, showing it can effectively assist government departments, owners, and managers in the dynamic prediction of project performance in the future, and it can help to achieve real-time warnings, so as to improve the performance and satisfaction of a project. In addition, the research results, after experts' feedback, could provide specific performance management strategies for future project management. For project managers, these suggestions could greatly reduce the risk of future project execution.
The complexity of building projects varies and it is difficult for all the participating teams to establish the cause of poor project performance based on their existing knowledge, or on the rule of thumb. Moreover, in the current control operation, it is impossible to devote all the resources to managing all the projects. Hence, the artificial intelligence approach and data mining techniques can effectively transform the data into useful information and knowledge. They can establish a prevention mechanism and management plan for poor project execution, which will be the standard plan in project management. Finally, the methods and management response measures proposed in this study can provide general advice to relevant governments, stakeholders, and researchers. The number of cases may be somewhat small to operate the ANN. However, judging from the cases in 2019, only 7 teaching and administrative buildings were major projects (over NTD 200 million). Furthermore, 62 cases collected within ten years of the investigation period have been able to fully reflect the representativeness of the research cases. If the number of cases can be continuously and completely increased in the future, it is believed that the results of predicting the projects' performances will be more accurate and robust.

\section{Author contributions}

Yi-Kai Juan contributed to the establishment of the prediction model, data analysis, and article writing. Ling-Er Liou contributed to reviews of relevant studies, data collection and analysis, and discussion of results.

\section{Disclosure statement}

All the authors have no conflict of interest.

\section{References}

Adeli, H., \& Wu, M. (1998). Regularization neural network for construction cost estimation. Journal of Construction Engineering and Management, 124(4), 18-24. https://doi.org/10.1061/(ASCE)0733-9364(1998)124:1(18)

Agrawal, R., Imieliński, T., \& Swami, A. (1993). Mining association rules between sets of items in large databases. In $A C M$ SIGMOD International Conference on Management of Data (pp. 207-216), Washington D.C., USA.

https://doi.org/10.1145/170036.170072

Ahadzie, D. K., Proverbs, D. G., \& Olomolaiye, P. O. (2008). Critical success criteria for mass house building projects in developing countries. International Journal of Project Management, 26(6), 675-687.

https://doi.org/10.1016/j.ijproman.2007.09.006

Alaloul, W. S., Lieew, M. S., Zawawi, N. A. W., Mohammed, B. S., \& Adamu, M. (2018). An Artificial neural networks (ANN) model for evaluating construction project performance based on coordination factors. Cogent Engineering, 5(1), 1507657. https://doi.org/10.1080/23311916.2018.1507657

Al-Momani, A. H. (1996). Construction cost prediction for public school buildings in Jordan. Construction Management and Economics, 14(4), 311-317.

https://doi.org/10.1080/014461996373386 
Alzahrani, J. I., \& Emsley, M. W. (2013). The impact of contractors' attributes on construction project success: a post construction evaluation. International Journal of Project Management, 31, 313-322.

https://doi.org/10.1016/j.ijproman.2012.06.006

Aretoulis, G. N., Angelides, D. C., Kalfakakou, G. P., Fotiadis, G. S., \& Anastasiadis, K. I. (2006). A prototype system for the prediction of final cost in construction projects. International Journal of Operational Research, 6(3), 423-432. https://doi.org/10.1007/BF02941260

Aretoulis, G. N. (2019). Neural network models for actual cost prediction in Greek public highway projects. International Journal of Project Organisation and Management, 11(1), 4164. https://doi.org/10.1504/IJPOM.2019.098712

Armaghani, D. J., Mohamad, E. T., Narayanasamy, M.S., Narita, N., \& Yagiz, S. (2017). Development of hybrid intelligent models for predicting TBM penetration rate in hard rock condition. Tunnelling and Underground Space Technology, 63, 29-43. https://doi.org/10.1016/j.tust.2016.12.009

Baccarini, D. (1999). The logical framework method for defining project success. Project Management Journal, 30(4), 25-32. https://doi.org/10.1177/875697289903000405

Bagaya, O., \& Song, J. (2016). Empirical study of factors influencing schedule delays of public construction projects in Burkina Faso. Journal of Management in Engineering, 32(5), 05016014. https://doi.org/10.1061/(ASCE)ME.1943-5479.0000443

Barraaza, G. A., Back, W. E., \& Mata, F. (2000). Probabilistic monitoring of project performance using SS-curves. Journal of Construction Engineering and Management, 126(2), 142-148. https://doi.org/10.1061/(ASCE)0733-9364(2000)126:2(142)

Bassioni, H., Price, A., \& Hassan, T. (2004). Performance measurement in construction. Journal of Management in Engineering, 20(2), 42-50. https://doi.org/10.1061/(ASCE)0742-597X(2004)20:2(42)

Bryde, D. J., \& Wright, G. H. (2007). Project management priorities and the link with performance management systems. Project Management Journal, 38(4), 5-11. https://doi.org/10.1002/pmj.20014

Chan, A. P. C., Scott, D., \& Chan, A. P. L. (2004). Factors affecting the success of a construction project. Journal of Construction Engineering and Management, 130(1), 153-155. https://doi.org/10.1061/(ASCE)0733-9364(2004)130:1(153)

Chen, W. T., \& Huang, Y. H. (2006). Approximately predicting the cost and duration of school reconstruction projects in Taiwan. Construction Management and Economics, 24(12), 1231-1239. https://doi.org/10.1080/01446190600953805

Cristóbal, J. R. S. (2017). The S-curve envelope as a tool for monitoring and control of projects. Procedia Computer Science, 121, 756-761. https://doi.org/10.1016/j.procs.2017.11.097

Doloi, H., Sawhney, A., Iyer, K. C., \& Rentala, S. (2012). Analysing factors affecting delays in Indian construction projects. International Journal of Project Management, 30(4), 479-489. https://doi.org/10.1016/j.ijproman.2011.10.004

Enshassi, A., Mohamed, S., \& Abushaban, S. (2008). Factors affecting the performance of construction projects in the Gaza strip. Journal of Civil Engineering and Management, 15(3), 269-280. https://doi.org/10.3846/1392-3730.2009.15.269-280

Faridi, A., \& El-Sayegh, S. (2006). Significant factors causing delay in the UAE construction industry. Construction Management and Economics, 24(11), 1167-1176. https://doi.org/10.1080/01446190600827033

Flanagan, R., Lu, W., Shen, L., \& Jewell, C. (2006). Competitiveness in construction: a critical review of research. Construction Management and Economics, 25(9), 989-1000. https://doi.org/10.1080/01446190701258039
Fleming, Q. W., \& Koppelman, J. M. (2010). Earned value project management (4th ed.). Project Management Institute.

Fragkakis, N., Lambropoulos, S., \& Pantouvakis, J.-P. (2010). A cost estimate method for bridge superstructures using regression analysis and bootstrap. Organization, Technology \& Management in Construction: An International Journal, 2(2), 182-190.

Gudiene, N., Banaitis, A., Podvezko, V., \& Banaitiene, N. (2014). Identification and evaluation of the critical success factors for construction projects in Lithuania: AHP approach. Journal of Civil Engineering and Management, 20(3), 350-359.

https://doi.org/10.3846/13923730.2014.914082

Gunduz, M., \& Yahya, A. M. A. (2018). Analysis of project success factors in construction industry. Technological and Economic Development of Economy, 24(1), 67-80.

https://doi.org/10.3846/20294913.2015.1074129

Hajdu, M., \& Bokor, O. (2016). Sensitivity analysis in PERT networks: Does activity duration distribution matter? Automation in Construction, 65, 1-8.

https://doi.org/10.1016/j.autcon.2016.01.003

Haponava, T., \& Al-jibouri, S. (2012). Proposed system for measuring project performance using process-based key performance Indicators. Journal of Management in Engineering, 28(2), 140-149.

https://doi.org/10.1061/(ASCE)ME.1943-5479.0000078

Hardie, M., \& Saha, S. (2009). Builders' perceptions of lowest cost procurement and its impact on quality. The Australasian Journal of Construction Economics and Building, 9(1), 1-8. https://doi.org/10.5130/AJCEB.v9i1.3009

Hola, B., \& Schabowicz, K. (2010). Estimation of earthworks execution time cost by means of artificial neural networks. Automation in Construction, 19(5), 570-579. https://doi.org/10.1016/j.autcon.2010.02.004

Huang, J., Koopialipoor, M., \& Armaghani, D. J. (2020). A combination of fuzzy Delphi method and hybrid ANN-based systems to forecast ground vibration resulting from blasting. Scientific Reports, 10, 19397.

https://doi.org/10.1038/s41598-020-76569-2

Ibbs, W., Nguyen, L. D., \& Simonian, L. (2011). Concurrent delays and apportionment of damages. Journal of Construction Engineering and Management, 137(2), 119-126. https://doi.org/10.1061/(ASCE)CO.1943-7862.0000259

Jha, K. N., \& Iyer, K. C. (2007). Commitment, coordination, competence and the iron triangle. International Journal of Project Management, 25(5), 527-540.

https://doi.org/10.1016/j.ijproman.2006.11.009

Juan, Y. K., Hsu, Y. H., \& Xie, X. (2017). Identifying customer behavioral factors and price premiums of green building purchasing. Industrial Marketing Management, 64, 36-43. https://doi.org/10.1016/j.indmarman.2017.03.004

Kamsu-Foguem, B., Rigal, F., \& Mauget, F. (2013). Mining association rules for the quality improvement of the production process. Expert Systems with Applications, 40(4), 1034-1045. https://doi.org/10.1016/j.eswa.2012.08.039

Kog, Y. C., \& Loh, P. K. (2012). Critical success factors for different components of construction projects. Journal of Construction Engineering and Management, 138(4), 520-528. https://doi.org/10.1061/(ASCE)CO.1943-7862.0000464

Leung, M. Y., Ng, S. T., \& Cheung, S. O. (2004). Measuring construction project participant satisfaction. Construction Management and Economics, 22(3), 319-331. https://doi.org/10.1080/01446190320000000000

Li, D., Koopialipoor, M., \& Armaghani, D. J. (2021). A combination of Fuzzy Delphi method and ANN-based models to in- 
vestigate factors of flyrock induced by mine blasting. Natural Resources Research, 30, 1905-1924.

https://doi.org/10.1007/s11053-020-09794-1

Ling, F. Y. Y., \& Liu, M. (2004). Using neural network to predict performance of design-build projects in Singapore. Building and Environment, 39(10), 1263-1274.

https://doi.org/10.1016/j.buildenv.2004.02.008

Lin, G., Shen, G., Sun, M., \& Kelly, J. (2011). Identification of key performance indicators for measuring the performance of value management studies in construction. Journal of Construction Engineering and Management, 137(9), 698-706. https://doi.org/10.1061/(ASCE)CO.1943-7862.0000348

Liu, B., Hsu, W., Chen, S., \& Ma, Y. (2000). Analyzing the subjective interestingness of association rules. IEEE Intelligent Systems and their Applications, 15(5), 47-55.

https://doi.org/10.1109/5254.889106

Kaufmann, A., \& Gupta, M. M. (1988). Fuzzy mathematical models in engineering and management science. North-Holland.

Kuo, Y. F., \& Chen, P. C. (2008). Constructing performance appraisal indicators for mobility of the service industries using Fuzzy Delphi Method. Expert Systems with Applications, 35(4), 1930-1939. https://doi.org/10.1016/j.eswa.2007.08.068

Mansingh, G., Osei-Bryson, K. M., \& Reichgelt, H. (2011). Using ontologies to facilitate post-processing of association rules by domain experts. Information Science, 181(3), 419-434. https://doi.org/10.1016/j.ins.2010.09.027

Mitkus, S., \& Trinkūnienè, E. (2008). Reasoned decisions in construction contracts evaluation. Technological and Economic Development of Economy, 14(3), 402-416. https://doi.org/10.3846/1392-8619.2008.14.402-416

Mohamad, E. T., Armaghani, D. J., Momeni, E., \& Abad, S. V. A. N. K. (2014). Prediction of the unconfined compressive strength of soft rocks: a PSO-based ANN approach. Bulletin of Engineering Geology and the Environment, 74, 745-757. https://doi.org/10.1007/s10064-014-0638-0

Murray, T. J., Pipino, L. L., \& van Gigch, J. P. (1985). A pilot study of fuzzy set modification of Delphi. Human Systems Management, 5(1), 76-80. https://doi.org/10.3233/HSM-1985-5111

National Development Council. (2020). Overview of the project implementation of Ministry of Education. https://join.gov.tw/ acts/gpivp/6223bf3f-206e-425a-9872-b1f2a9ad4281/index

Nassar, N., \& AbouRizk, S. (2014). Practical application for integrated performance measurement of construction projects. Journal of Management in Engineering, 30(6), 04014027. https://doi.org/10.1061/(ASCE)ME.1943-5479.0000287

Olafsson, S., Li, X., \& Wu, S. (2008). Operations research and data mining. European Journal of Operational Research, 187(3), 1429-1448. https://doi.org/10.1016/j.ejor.2006.09.023

Patanakul, P., Kwak, Y.H., Zwikael, O., \& Liu, M. (2016). What impacts the performance of large-scale government projects? International Journal of Project Management, 34(3), 452-466. https://doi.org/10.1016/j.ijproman.2015.12.001

Perng, Y. H., Juan, Y. K., \& Chien, S. F. (2006). Exploring the bidding situation for economically most advantageous tender projects using a bidding game. Journal of Construction Engineering and Management, 132(10), 1037-1042. https://doi.org/10.1061/(ASCE)0733-9364(2006)132:10(1037)

Petroutsatou, K., Georgopoulos, E., Lambropoulos, S., \& Pantouvakis, J. (2011). Early cost estimating of road tunnel construction using neural networks. Journal of Construction Engineering and Management, 138(6), 679-687.

https://doi.org/10.1061/(ASCE)CO.1943-7862.0000479
Public Construction Commission. (2020). Construction management information system. https://cmdweb.pcc.gov.tw//

Rozenes, S., Vitner, G., \& Spraggett, S. (2004). MPCS: Multidimensional project control system. International Journal of Project Management, 22(2), 109-118. https://doi.org/10.1016/S0263-7863(03)00002-4

Sambasivan, M., \& Soon, Y. (2007). Causes and effects of delays in Malaysian construction industry. International Journal of Project Management, 25, 517-526. https://doi.org/10.1016/j.ijproman.2006.11.007

Santoso, D. S., \& Gallage, P. G. M. P. (2019). Critical factors affecting the performance of large construction projects in developing countries: A case study of Sri Lanka. Journal of Engineering, Design and Technology, 18(3), 531-556. https://doi.org/10.1108/JEDT-05-2019-0130

Sanvido, V., Grobler, F., Parfitt, K., Guvenis, M., \& Coyle, M. (1992). Critical success factors for construction projects. Journal of Construction Engineering and Management, 118(1), 94-111.

https://doi.org/10.1061/(ASCE)0733-9364(1992)118:1(94)

Shrestha, P. P., \& Zeleke, H. (2018). Effect of change orders on cost and schedule overruns of school building renovation projects. Journal of Legal Affairs and Dispute Resolution in Engineering and Construction, 10(4), 04518018. https://doi.org/10.1061/(ASCE)LA.1943-4170.0000271

Sullivan, J., El Asmar, M., Chalhoub, J., \& Obeid, H. (2017). Two decades of performance comparisons for design-build, construction manager at risk, and design-bid-build: quantitative analysis of the state of knowledge on project cost, schedule, and quality. Journal of Construction Engineering and Management, 143(6), 04017009.

https://doi.org/10.1061/(ASCE)CO.1943-7862.0001282

Tabish, S. Z., \& Jha, K. N. (2012). Success traits for a construction project. Journal of Construction Engineering and Management, 138(10), 1131-1138.

https://doi.org/10.1061/(ASCE)CO.1943-7862.0000538

Telikani, A., Gandomi, A. H., \& Shahbahrami, A. (2020). A survey of evolutionary computation for association rule mining. Information Science, 524, 318-352.

https://doi.org/10.1016/j.ins.2020.02.073

Ting, C. K., Liaw, R. T., Wang, T. C., \& Hong, T. P. (2018). Mining fuzzy association rules using a memetic algorithm based on structure representation. Memetic Computing, 10, 15-28. https://doi.org/10.1007/s12293-016-0220-3

Wang, Y. R., Yu, C. Y., \& Chan, H. H. (2012). Predicting construction cost and schedule success using artificial neural networks ensemble and support vector machines classification models. International Journal of Project Management, 30(4), 470-478. https://doi.org/10.1016/j.ijproman.2011.09.002

Wei, W. L., \& Chang, W. C. (2008). Analytic network process-based model for selecting an optimal product design solution with zero-one goal programming. Journal of Engineering Design, 19(1), 15-44. https://doi.org/10.1080/09544820601186054

Yang, J., Shen, G. Q., Drew, D. S., \& Ho, M. (2010). Critical success factors for stakeholder management: construction practitioners' perspectives. Journal of Construction Engineering and Management, 136(7), 778-786.

https://doi.org/10.1061/(ASCE)CO.1943-7862.0000180

Zavadskas, E. K., Vilutiene, T., Turskis, Z., \& Saparauskas, J. (2014). Multi-criteria analysis of projects' performance in construction. Archives of Civil and Mechanical Engineering, 14(1), 114-121. https://doi.org/10.1016/j.acme.2013.07.006 


\section{APPENDIX 1}

\section{Detailed information on 62 cases}

\begin{tabular}{|c|c|c|c|c|c|c|c|c|c|c|c|c|c|c|c|c|c|c|c|c|c|c|c|}
\hline \multicolumn{12}{|c|}{ Planning \& design and bid-inviting phases } & \multicolumn{10}{|c|}{ Construction phase } & \multirow{2}{*}{ 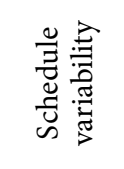 } & \multirow{2}{*}{ ن } \\
\hline 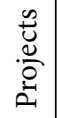 & $\overrightarrow{\mid r}$ & $\sum_{i}$ & $\sum_{\Sigma_{1}}^{N_{1}}$ & $\begin{array}{l}N_{1} \\
\text { 壵 }\end{array}$ & $\vec{a}$ & $\begin{array}{l}N_{1} \\
a_{1}\end{array}$ & $\sum_{i}^{m}$ & $\sum_{\Delta}^{\sigma_{1}}$ & $\begin{array}{l}m_{1} \\
n_{1}\end{array}$ & $\begin{array}{l}\nabla_{1} \\
\Omega_{1}\end{array}$ & $\begin{array}{l}n_{1} \\
n_{1}^{\prime}\end{array}$ & $\begin{array}{l}m \\
\text { I I }\end{array}$ & $\begin{array}{l}\sigma_{1} \\
\text { 㞬 }\end{array}$ & $\begin{array}{l}n \\
1 \\
1\end{array}$ & $\begin{array}{l}\sigma_{1} \\
\frac{1}{2}\end{array}$ & $\overrightarrow{a_{1}}$ & $\begin{array}{l}a_{1} \\
\hat{a}_{1}\end{array}$ & $\sum_{1}^{v_{1}}$ & $\begin{array}{l}0, \\
I_{1} \\
2\end{array}$ & $\begin{array}{l}\vec{H} \\
y_{1}\end{array}$ & $\sum_{\Omega}^{\infty}$ & & \\
\hline 1 & 1 & 0 & 0 & 1 & 1 & 0 & 1 & 2 & 0 & 540 & 4 & 3 & 1 & 0 & 0 & 0 & 0 & 0 & 0 & 0 & 0 & Good & Good \\
\hline 2 & 1 & 1 & 1.66 & 2 & 1 & 1 & 1 & 3 & 1 & 750 & 5.6 & 0.18 & 2 & 0 & 1 & 1 & 0 & 1 & . & 1 & 0 & Poor & Poor \\
\hline 3 & 1 & 1 & 0 & 1 & 0 & 0 & 1 & 3 & 0 & 780 & 11.1 & 1.95 & 1 & 0 & 0 & 0 & 0 & 0 & $\sigma$ & 0 & 0 & Good & Good \\
\hline 4 & 1 & 0 & 0 & 1 & 0 & 0 & 1 & 3 & 0 & 750 & 6.6 & 1.81 & 1 & 0 & 0 & 0 & 0 & 0 & 0 & 0 & 0 & Good & Good \\
\hline 5 & 0 & 0 & 1 & 1 & 0 & 0 & 1 & 3 & 0 & 910 & 6.2 & 1 & 2 & 0 & 0 & 0 & 0 & 0 & 0 & 0 & 0 & Excellent & Good \\
\hline 6 & 1 & 0 & 0 & 1 & 0 & 0 & 1 & 2 & 0 & 680 & 4.2 & 1 & 1 & 0 & 0 & 0 & 0 & 0 & 0 & 0 & 0 & Good & Good \\
\hline 7 & 0 & 1 & 1 & 2 & 0 & 0 & 1 & 3 & 3 & 450 & 1.2 & 0.50 & 2 & 0 & 1 & 0 & 1 & 1 & 0 & 1 & 0 & Poor & $\mathrm{Bad}$ \\
\hline 8 & 14 & 1 & 0.19 & 2 & 1 & 1 & 1 & 1 & 0 & 920 & 23.1 & 0.06 & 2 & 1 & 1 & 16 & 1 & 1 & 0 & 0 & 1 & $\mathrm{Bad}$ & $\mathrm{Bad}$ \\
\hline 9 & 0 & 1 & 1 & 2 & 0 & 1 & 1 & 2 & 0 & 730 & 3.84 & 0.50 & 2 & 0 & 0 & 1 & 0 & 1 & 1 & 1 & 1 & $\mathrm{Bad}$ & Poor \\
\hline 10 & 2 & 1 & 1 & 1 & 1 & 0 & 1 & 2 & 0 & 758 & 3.88 & 0.40 & 2 & 1 & 1 & 1 & 0 & 1 & 0 & 1 & 0 & $\mathrm{Bad}$ & Poor \\
\hline 11 & 0 & 1 & 0.18 & 2 & 0 & 0 & 1 & 1 & 0 & 910 & 0.19 & 0.50 & 2 & 0 & 1 & $\mathrm{~J}$ & 0 & 1 & 0 & 1 & 0 & $\mathrm{Bad}$ & $\mathrm{Bad}$ \\
\hline 12 & 1 & 0 & 0 & 2 & 1 & 0 & 1 & 2 & 1 & 600 & 2.29 & 0.40 & 2 & 0 & 1 & 3 & 0 & 1 & 0 & 1 & 0 & Bad & Poor \\
\hline 13 & 2 & 0 & 0.1 & 2 & 1 & 0 & 1 & 2 & 0 & 686 & 2.45 & 1 & 1 & 0 & 1 & 0 & 0 & 0 & 0 & 0 & 0 & Excellent & $\mathrm{Bad}$ \\
\hline 14 & 0 & 0 & 0 & 1 & 0 & 0 & 1 & 1 & 0 & 910 & 2.65 & 1.05 & 1 & 0 & 0 & 0 & 0 & 0 & 0 & 0 & 0 & Good & Good \\
\hline 15 & 1 & 1 & 0.1 & 2 & 1 & 0 & 2 & 1 & 0 & 675 & 6.26 & 0.90 & 2 & 1 & 1 & 1 & 0 & 1 & 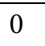 & 1 & 1 & $\mathrm{Bad}$ & $\mathrm{Bad}$ \\
\hline 16 & 0 & 0 & 0.1 & 1 & 0 & 0 & 1 & 2 & 0 & 872 & 2.05 & 1 & 1 & 0 & 0 & 2 & 0 & 0 & 0 & 0 & 0 & Excellent & Good \\
\hline 17 & 0 & 0 & 0.1 & 2 & 0 & 0 & 1 & 2 & 2 & 730 & 2.86 & 0.50 & 2 & 0 & 1 & 2 & 0 & 1 & 0 & 0 & 0 & $\mathrm{Bad}$ & $\mathrm{Bad}$ \\
\hline 18 & 2 & 1 & 1.08 & 2 & 0 & 1 & 1 & 2 & 1 & 517 & 5.52 & 0.38 & 2 & 1 & 1 & 5 & 0 & 1 & 0 & 0 & 0 & $\mathrm{Bad}$ & Poor \\
\hline 19 & 2 & 1 & 0.24 & 2 & 1 & 1 & 1 & 2 & 1 & 1240 & 2.90 & 0.90 & 2 & 0 & 1 & 3 & 0 & 0 & 0 & 1 & 1 & Poor & $\mathrm{Bad}$ \\
\hline 20 & 0 & 0 & 0 & 2 & 0 & 0 & 1 & 2 & 2 & 760 & 8.87 & 0.31 & 2 & 1 & 1 & 1 & 0 & 1 & 1 & 1 & 0 & Bad & Poor \\
\hline 21 & 0 & 0 & 0 & 2 & 0 & 1 & 1 & 2 & 1 & 838 & 2.01 & 0.48 & 2 & 0 & 1 & 0 & c & 1 & 0 & 0 & 1 & $\mathrm{Bad}$ & Poor \\
\hline 22 & 0 & 0 & 0 & 2 & 0 & 0 & 1 & 2 & 1 & 900 & 5.76 & 0.82 & 2 & 0 & 1 & 0 & 0 & 1 & 0 & 1 & 0 & $\mathrm{Bad}$ & Poor \\
\hline 23 & 0 & 1 & 0.18 & 2 & 0 & 1 & 1 & 2 & 0 & 920 & 4.87 & 21 &  & 0 & 1 & 0 & 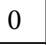 & 0 & 0 & 1 & 1 & $\mathrm{Bad}$ & Poor \\
\hline 24 & 1 & 1 & 0 & 2 & 0 & 0 & 1 & 2 & 0 & 1112 & 16.03 & 90 & 1 & 0 & 1 & 0 & 0 & 1 & 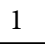 & 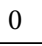 & 1 & $\mathrm{~B}$ & $\mathrm{Bad}$ \\
\hline 25 & 0 & 0 & 0 & 2 & 0 & 0 & 1 & 2 & 1 & 570 & 2.22 & 90 & 1 & 0 & 1 & 2 & 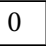 & 1 & 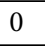 & 0 & 0 & $\mathrm{Bad}$ & $\mathrm{Bad}$ \\
\hline 26 & 0 & 1 & 2 & 1 & 0 & 1 & 1 & 2 & 0 & 600 & 3.54 & 5 & 2 & 0 & 1 & 0 & 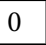 & 0 & 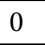 & 1 & 1 & $\mathrm{R}$ & Poor \\
\hline 27 & 0 & 0 & 0.15 & 2 & 1 & 1 & 1 & 3 & 1 & 396 & 2.67 & 0.41 & 2 & 1 & 1 & 1 & 1 & 1 & 1 & 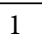 & 0 & Bad & Poor \\
\hline 28 & 0 & 0 & 0 & 1 & 2 & 0 & 1 & 2 & 0 & 840 & 4.29 & 16 & 1 & 0 & O & 0 & 0 & 0 & 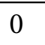 & 0 & 0 & Good & Good \\
\hline 29 & 0 & 1 & 1 & 2 & 2 & 0 & 1 & 2 & 0 & 380 & 2.95 & 0.17 & 2 & 1 & 1 & 1 & 0 & 1 & 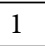 & 1 & 0 & $\mathrm{Bad}$ & Poor \\
\hline 30 & 0 & 1 & 1 & 2 & 3 & 1 & 1 & 2 & 0 & 360 & 2.14 & 0.23 & 0 & 0 & 1 & 0 & 0 & . & 0 & 1 & 0 & $\mathrm{Bad}$ & Poor \\
\hline 31 & 1 & 1 & 1 & 2 & 3 & 1 & 1 & 2 & 2 & 430 & 3.22 & 0.16 & 2 & 1 & 1 & 1 & 0 & 4 & 0 & 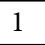 & 0 & $\mathrm{Bad}$ & Poor \\
\hline 32 & 0 & 1 & 0.49 & 2 & 1 & 1 & 1 & 7 & 0 & 730 & 2.95 & 0.34 & 2 & 0 & 1 & 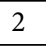 & 0 & 1 & 0 & 0 & 0 & $\mathrm{Bad}$ & Poor \\
\hline 33 & 1 & 1 & 0 & 1 & 0 & 0 & 1 & 2 & 0 & 830 & 3.98 & 1 & 1 & 0 & 0 & 3 & 0 & 0 & 0 & 0 & 1 & Good & Good \\
\hline 34 & 0 & 1 & 0.19 & 2 & 2 & 1 & 1 & 2 & 1 & 1331 & 2.26 & 0.16 & 2 & 0 & 1 & 1 & 1 & 1 & 0 & 1 & 1 & $\mathrm{Bad}$ & Poor \\
\hline 35 & 0 & 0 & 0.1 & 2 & 1 & 0 & 1 & 2 & 1 & 540 & 2.83 & 0.14 & 2 & 0 & 0 & 14 & 0 & 1 & 1 & 0 & 1 & Poor & Poor \\
\hline 36 & 1 & 0 & 0 & 1 & 0 & 0 & 1 & 2 & 0 & 700 & 3.37 & 1 & 1 & 0 & 0 & 28 & 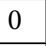 & 0 & 0 & 0 & 0 & Good & Good \\
\hline 37 & 0 & 1 & 1 & 2 & 0 & 1 & 1 & 2 & 1 & 500 & 8.58 & 0.13 & 2 & 1 & 1 & 0 & 0 & 1 & 0 & 1 & 0 & $\mathrm{Bad}$ & $\mathrm{Bad}$ \\
\hline 38 & 1 & 1 & 1 & 2 & 0 & 1 & 1 & 2 & 5 & 750 & 5.84 & 0.50 & 2 & 0 & . & 0 & 0 & 1 & 1 & 0 & 1 & $\mathrm{Bad}$ & Poor \\
\hline 39 & 2 & 1 & 0 & 2 & 4 & 0 & 1 & 2 & 0 & 470 & 2.70 & 0.50 & 2 & 0 & 0 & 4 & 0 & 1 & 0 & 1 & 0 & $\mathrm{Bad}$ & Poor \\
\hline 40 & 1 & 0 & 0 & 2 & 2 & 0 & 1 & 2 & 0 & 540 & 1.88 & 0.40 & 2 & 0 & 1 & 2 & 0 & 0 & 0 & 1 & 0 & $\mathrm{Bad}$ & Poor \\
\hline 41 & 23 & 1 & 0 & 1 & 0 & 0 & 1 & 3 & 10 & 704 & 2.06 & 0.50 & 2 & 0 & 1 & 2 & 0 & 0 & 0 & 1 & 0 & $\mathrm{Bad}$ & Poor \\
\hline 42 & 0 & 1 & 0.36 & 2 & 1 & 0 & 1 & 3 & 1 & 490 & 4.54 & 0.40 & 2 & 0 & 1 & 3 & 1 & 1 & 0 & 1 & 0 & $\mathrm{Bad}$ & Poor \\
\hline 43 & 0 & 1 & 0.15 & 2 & 3 & 1 & 1 & 2 & 1 & 550 & 2.70 & 0.40 & 2 & 0 & 1 & 1 & 0 & 0 & 1 & 1 & 1 & $\mathrm{Bad}$ & $\mathrm{Bad}$ \\
\hline 44 & 0 & 0 & 0.18 & 2 & 3 & 1 & 1 & 2 & 0 & 730 & 4.23 & 0.90 & 2 & 0 & 1 & 1 & 0 & 1 & 0 & 1 & 1 & $\mathrm{Bad}$ & $\mathrm{Bad}$ \\
\hline 45 & 1 & 1 & 0.92 & 2 & 1 & 1 & 1 & 2 & 1 & 672 & 4.27 & 0.63 & 2 & 1 & 1 & 3 & 0 & 1 & 1 & 1 & 0 & $\mathrm{Bad}$ & Poor \\
\hline 46 & 2 & 1 & 0.17 & 1 & 2 & 1 & 1 & 2 & 0 & 491 & 2 & 0.50 & 2 & 1 & 0 & 1 & 0 & 0 & 0 & 0 & 1 & Poor & Poor \\
\hline 47 & 0 & 0 & 0.78 & 2 & 0 & 1 & 1 & 2 & 3 & 730 & 2.25 & 0.44 & 2 & 0 & 1 & 5 & 1 & 1 & 1 & 0 & 1 & $\mathrm{Bad}$ & Poor \\
\hline
\end{tabular}


End of Appendix 1

\begin{tabular}{|c|c|c|c|c|c|c|c|c|c|c|c|c|c|c|c|c|c|c|c|c|c|c|c|}
\hline \multicolumn{12}{|c|}{ Planning \& design and bid-inviting phases } & \multicolumn{10}{|c|}{ Construction phase } & \multirow{2}{*}{ 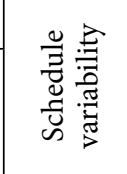 } & \multirow{2}{*}{ 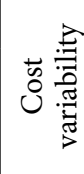 } \\
\hline 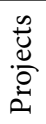 & $\overrightarrow{\mid}$ & $\overrightarrow{\sum_{1}}$ & $\sum_{\Sigma}^{N}$ & $\begin{array}{l}N_{1} \\
I^{\prime}\end{array}$ & $\overrightarrow{\underline{a}}$ & $\begin{array}{l}v_{1} \\
\hat{a}_{1}\end{array}$ & $\sum_{1}^{m}$ & $\sum_{\Omega}^{+}$ & $\begin{array}{l}m \\
\vec{a}\end{array}$ & $\frac{H_{1}}{2}$ & $\begin{array}{l}n \\
\stackrel{n}{2}\end{array}$ & $\begin{array}{l}m_{1} \\
\text { 㞬 }\end{array}$ & $\begin{array}{l}F_{1} \\
\text { 壵 }\end{array}$ & $\begin{array}{l}n_{1} \\
\text { 㞬 }\end{array}$ & $\frac{\sigma_{1}}{2}$ & $\vec{a}$ & $\vec{a}$ & $\sum_{i}^{\sigma_{1}}$ & $\begin{array}{l}0 \\
0_{1} \\
L_{1}\end{array}$ & $\begin{array}{l}H_{1} \\
\text { 至 }\end{array}$ & $\sum_{2}^{\infty}$ & & \\
\hline 48 & 1 & 1 & & 2 & 1 & 1 & 1 & . & 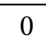 & 660 & 0.38 & 0.10 & 2 & 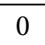 & 0 & 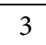 & 0 & & 0 & 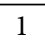 & . & Bad & Bad \\
\hline 49 & 0 & 0 & 0.75 & 2 & 0 & 0 & 1 & 2 & 1 & 868 & 6.49 & 0.50 & 2 & 1 & 1 & 0 & 0 & 1 & 0 & 1 & 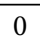 & Bad & $\mathrm{Bad}$ \\
\hline 50 & 1 & 0 & 0 & 1 & 1 & 0 & 2 & 1 & 0 & 727 & 9.07 & 1.29 & 1 & 0 & 0 & 0 & 0 & 0 & 0 & 0 & 0 & Good & Poor \\
\hline 51 & 0 & 0 & 0 & 2 & 0 & 0 & 1 & 2 & 0 & 600 & 2.18 & 1 & 1 & 0 & 0 & 0 & 0 & 0 & 0 & 0 & 0 & Excellent & Poor \\
\hline 52 & 3 & 1 & .45 & 2 & 0 & 0 & 1 & - & 0 & 547 & 4.86 & 0.40 & 2 & 1 & 1 & 3 & 0 & 1 & 0 & 1 & 1 & $\mathrm{Bad}$ & $\mathrm{Bad}$ \\
\hline 53 & 4 & 1 & 0.31 & 1 & 1 & 0 & 1 & 2 & 0 & 500 & 1.19 & 1 & 1 & 0 & 0 & 4 & 0 & 0 & 0 & 0 & 0 & Good & Poor \\
\hline 54 & 1 & 1 & 1 & 2 & 1 & 1 & 1 & 1 & 1 & 400 & 1.94 & 0.52 & 2 & 1 & 1 & 4 & 1 & 1 & 0 & 0 & 1 & $\mathrm{Bad}$ & Poor \\
\hline 55 & 1 & 1 & 1 & 2 & 1 & 1 & 1 & 2 & 1 & 540 & 8.26 & 0.24 & 2 & 1 & 1 & 0 & 1 & 1 & 1 & 1 & 1 & $\mathrm{Bad}$ & Poor \\
\hline 56 & 4 & 0 & 0 & 1 & 0 & 0 & 1 & 2 & 0 & 394 & 1.94 & 1 & 1 & 0 & 0 & 4 & 0 & 0 & 0 & 0 & 0 & Good & Poor \\
\hline 57 & 1 & 0 & 1 & 2 & 0 & 1 & 1 & 2 & 0 & 600 & 6.23 & 0.50 & 2 & 1 & 1 & 2 & 0 & 1 & 0 & 1 & 1 & $\mathrm{Bad}$ & Poor \\
\hline 58 & 1 & 0 & 0.38 & 1 & 1 & 0 & 1 & 3 & 3 & 510 & 2.25 & 1 & 1 & 0 & 0 & 0 & 0 & 0 & 0 & 0 & 0 & Good & Good \\
\hline 59 & 1 & 0 & 0.19 & 2 & 0 & 1 & 1 & 3 & 3 & 687 & 2.19 & 0.80 & 2 & 0 & 1 & 1 & 0 & 0 & 0 & 1 & 0 & Poor & $\mathrm{Bad}$ \\
\hline 60 & 0 & 0 & 0 & 1 & 0 & 0 & 1 & 3 & 0 & 729 & 3.62 & 1 & 1 & 0 & 0 & 0 & 0 & 0 & 0 & 0 & 0 & Good & Poor \\
\hline 61 & 0 & 0 & 0 & 1 & 2 & 0 & 1 & 2 & 0 & 800 & 5.16 & 1.55 & 1 & 0 & 0 & 0 & 0 & 0 & 0 & 0 & 0 & Good & Good \\
\hline 62 & 1 & 1 & 1 & 2 & 1 & 0 & 1 & 2 & 0 & 690 & 10.20 & 0.90 & 2 & 0 & 1 & 1 & 0 & 0 & 0 & 1 & 1 & $\mathrm{Bad}$ & Poor \\
\hline
\end{tabular}

\section{APPENDIX 2}

ANN model prediction results

\begin{tabular}{|c|c|c|c|c|c|c|c|c|c|c|c|c|c|c|c|}
\hline \multicolumn{12}{|c|}{ Planning \& design and bid-inviting phases } & \multicolumn{2}{|c|}{ Actual value } & \multicolumn{2}{|c|}{ ANN predictive value } \\
\hline $\begin{array}{l}\frac{\mathscr{U}}{0} \\
\stackrel{\tilde{D}}{0} \\
0\end{array}$ & $\overrightarrow{\mid}$ & $\overrightarrow{\Sigma^{\prime}}$ & $\sum_{\Sigma}^{N_{1}}$ & $\begin{array}{l}N_{1} \\
\text { 岌 }\end{array}$ & $\vec{a}$ & $\begin{array}{l}N_{1}^{\prime} \\
\hat{a}^{\prime}\end{array}$ & $\sum_{i}^{m_{1}}$ & $\sum_{\Sigma}^{H_{1}}$ & $\frac{m}{a}$ & $\begin{array}{l}H_{1}^{\prime} \\
\stackrel{a}{a}\end{array}$ & $\begin{array}{l}n \\
n \\
a\end{array}$ &  & 章 & 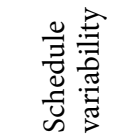 & 离 \\
\hline 1 & 1 & 0 & 0 & 1 & 1 & 0 & 1 & 2 & 0 & 540 & 4 & Good & Good & Good & Good \\
\hline 2 & 1 & 1 & 1.66 & 2 & 1 & 1 & 1 & 3 & 1 & 750 & 5.6 & Poor & Poor & Poor & Poor \\
\hline 5 & 0 & 0 & 1 & 1 & 0 & 0 & 1 & 3 & 0 & 910 & 6.2 & Excellent & Good & Good $^{*}$ & Good \\
\hline 6 & 1 & 0 & 0 & 1 & 0 & 0 & 1 & 2 & 0 & 680 & 4.2 & Good & Good & Good & Poor* \\
\hline 7 & 0 & 1 & 1 & 2 & 0 & 0 & 1 & 3 & 3 & 450 & 1.2 & Poor & $\mathrm{Bad}$ & Poor & $\mathrm{Bad}$ \\
\hline 9 & 0 & 1 & 1 & 2 & 0 & 1 & 1 & 2 & 0 & 730 & 3.84 & Bad & Poor & $\mathrm{Bad}$ & Poor \\
\hline 13 & 2 & 0 & 0.1 & 2 & 1 & 0 & 1 & 2 & 0 & 686 & 2.45 & Excellent & $\mathrm{Bad}$ & Good $^{*}$ & Bad \\
\hline 15 & 1 & 1 & 0.1 & 2 & 1 & 0 & 2 & 1 & 0 & 675 & 6.26 & $\mathrm{Bad}$ & Bad & $\mathrm{Bad}$ & $\mathrm{Bad}$ \\
\hline 16 & 0 & 0 & 0.1 & 1 & 0 & 0 & 1 & 2 & 0 & 872 & 2.05 & Excellent & Good & Excellent & Good \\
\hline 18 & 2 & 1 & 1.08 & 2 & 0 & 1 & 1 & 2 & 1 & 517 & 5.52 & Bad & Poor & $\mathrm{Bad}$ & Poor \\
\hline 20 & 0 & 0 & 0 & 2 & 0 & 0 & 1 & 2 & 2 & 760 & 8.87 & $\mathrm{Bad}$ & Poor & $\mathrm{Bad}$ & Poor \\
\hline 25 & 0 & 0 & 0 & 2 & 0 & 0 & 1 & 2 & 1 & 570 & 2.22 & $\mathrm{Bad}$ & $\mathrm{Bad}$ & $\mathrm{Bad}$ & Bad \\
\hline 28 & 0 & 0 & 0 & 1 & 2 & 0 & 1 & 2 & 0 & 840 & 4.29 & Good & Good & Good & Good \\
\hline 34 & 0 & 1 & 0.19 & 2 & 2 & 1 & 1 & 2 & 1 & 1331 & 2.26 & Bad & Poor & $\mathrm{Bad}$ & $\mathrm{Bad}^{\star}$ \\
\hline 35 & 0 & 0 & 0.1 & 2 & 1 & 0 & 1 & 2 & 1 & 540 & 2.83 & Poor & Poor & Poor & Poor \\
\hline 49 & 0 & 0 & 0.75 & 2 & 0 & 0 & 1 & 2 & 1 & 868 & 6.49 & $\mathrm{Bad}$ & Bad & $\mathrm{Bad}$ & Bad \\
\hline 51 & 0 & 0 & 0 & 2 & 0 & 0 & 1 & 2 & 0 & 600 & 2.18 & Excellent & Poor & Excellent & Good $^{*}$ \\
\hline 56 & 4 & 0 & 0 & 1 & 0 & 0 & 1 & 2 & 0 & 394 & 1.94 & Good & Poor & Good & Poor \\
\hline 61 & 0 & 0 & 0 & 1 & 2 & 0 & 1 & 2 & 0 & 800 & 5.16 & Good & Good & Poor* & Good \\
\hline
\end{tabular}

Note: ${ }^{\star}$ Prediction error. 